Award Number: W81XWH-13-1-0241

TITLE: Identifying P FP5 1 \$V that Regulate Neuroblastoma Cell Differentiation

PRINCIPAL INVESTIGATOR: Dr. Liqin Du

CONTRACTING ORGANIZATION: University of Texas Health Science Center San Antonio, TX 78229-3901

REPORT DATE: September 2014

TYPE OF REPORT: Annual

PREPARED FOR: U.S. Army Medical Research and Materiel Command

Fort Detrick, Maryland 21702-5012

DISTRIBUTION STATEMENT: Approved for Public Release;

Distribution Unlimited

The views, opinions and/or findings contained in this report are those of the author(s) and should not be construed as an official Department of the Army position, policy or decision unless so designated by other documentation. 


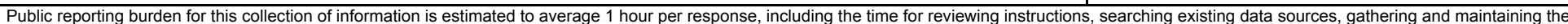

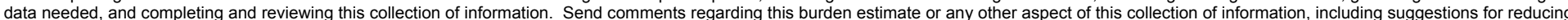

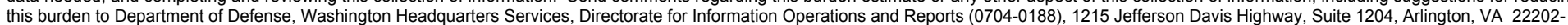

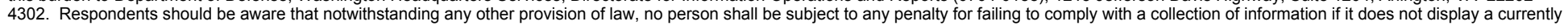
valid OMB control number. PLEASE DO NOT RETURN YOUR FORM TO THE ABOVE ADDRESS

1. REPORT DATE

4FQUFNCFS 2014

2. REPORT TYPE

3. DATES COVERED

Annual

1 Sep 2013 - 31 Aug 2014

4. TITLE AND SUBTITLE

Identifying NicroRNAs that 3egulate /euroblastoma \$ell

ifferentiation

5a. CONTRACT NUMBER

5b. GRANT NUMBER

8 98)

5c. PROGRAM ELEMENT NUMBER

6. AUTHOR(S)

Liqin Du, PhD; Zhenze Zhao, phD; Alexander Pertsemlidis, PhD; Xiuye Ma

5d. PROJECT NUMBER

5e. TASK NUMBER

5f. WORK UNIT NUMBER

E-Mail: dul2@uthscsa.edu

7. PERFORMING ORGANIZATION NAME(S) AND ADDRESS(ES)

UT Health Science Center at San Antonio

8. PERFORMING ORGANIZATION REPORT NUMBER

7703 Floyd Curl Drive.

San Antonio, TX 78229

9. SPONSORING / MONITORING AGENCY NAME(S) AND ADDRESS(ES)

10. SPONSOR/MONITOR'S ACRONYM(S)

U.S. Army Medical Research and Materiel Command

Fort Detrick, Maryland 21702-5012

11. SPONSOR/MONITOR'S REPORT

NUMBER(S)

12. DISTRIBUTION / AVAILABILITY STATEMENT

Approved for Public Release; Distribution Unlimited

\section{SUPPLEMENTARY NOTES}

\section{ABSTRACT}

We identified 14 microRNA candidates that induce neuroblastoma cell differentiation based on a high-content screening of neurite outgrowth — the morphological differentiation marker of neuroblastoma cells. We further validated that the identified top 5 microRNAs have general differentiation-inducing effects in neuroblastoma cells with different genetic backgrounds. Furthermore, we show that miR-506-3p, the most potent novel differentiationinducing microRNA identified in our screen, shows much more potent effect on reducing cell survival than other tumor suppressive miRNAs that were previously identified in neuroblastoma cells. Further investigation shows that miR-506-3p mimic significantly reduce the ability of neuroblastoma cells to form colonies, indicating their longterm capacity to inhibit neuroblastoma cell proliferation. Altogether, these results support the therapeutic potential of the differentiation-inducing microRNAs and support that, among these microRNAs, miR-506-3p has highest therapeutic potential to be applied as a differentiation agent to treat neuroblastoma.

\section{SUBJECT TERMS}

Neuroblastoma, miRNA, miRNA mimic, high-content screen (HCS), neurite outgrowth, cell differentiation

\begin{tabular}{|c|c|c|c|c|c|}
\hline \multicolumn{3}{|c|}{ 16. SECURITY CLASSIFICATION OF: } & \multirow{2}{*}{$\begin{array}{l}\text { 17. LIMITATION } \\
\text { OF ABSTRACT } \\
\text { Unclassified }\end{array}$} & \multirow{2}{*}{$\begin{array}{l}\text { 18. NUMBER } \\
\text { OF PAGES } \\
3\end{array}$} & \multirow{2}{*}{$\begin{array}{l}\text { 19a. NAME OF RESPONSIBLE PERSON } \\
\text { USAMRMC } \\
\text { 19b. TELEPHONE NUMBER (include area } \\
\text { code) }\end{array}$} \\
\hline $\begin{array}{l}\text { a. REPORT } \\
\text { Unclassified }\end{array}$ & $\begin{array}{l}\text { b. ABSTRACT } \\
\text { Unclassified }\end{array}$ & $\begin{array}{l}\text { c. THIS PAGE } \\
\text { Unclassified }\end{array}$ & & & \\
\hline
\end{tabular}


1. Introduction..................................................... 1

2. Keywords....................................................... 1

3. Overall Project Summary $\ldots \ldots \ldots \ldots \ldots \ldots \ldots \ldots \ldots \ldots \ldots \ldots \ldots \ldots \ldots \ldots . \ldots \ldots$

4. Key Research Accomplishments................................. 1

5. Conclusion............................................................. 3

6. Publications, Abstracts, and Presentations....................... 3

7. Inventions, Patents and Licenses.................................. 4

8. Reportable Outcomes............................................... 4

9. Other Achievements............................................ 4

10. References..................................................... 5

11. Appendices...................................................... 6 


\section{Progress Report}

$(0901 / 2013-08 / 31 / 2014)$

\section{Introduction}

The objective of this study is to use a functional high-content screening (HCS) approach to directly and comprehensively identify microRNAs (miRNAs) that induce neuroblastoma cell differentiation by applying a library of miRNA mimics used to raise the intracellular levels of miRNAs. Two specific aims are proposed: Aim 1, identify miRNAs that induce neuroblastoma cell differentiation by HCS; Aim 2, Validate the function of the identified miRNAs to induce cell differentiation and cell growth arrest in neuroblastoma cells.

\section{Keywords}

Neuroblastoma, miRNA, miRNA mimic, high-content screen (HCS), neurite outgrowth, differentiation, differentiation marker, cell growth arrest, MYCN amplification, colony formation

\section{Overall Project Summary}

In this reporting period, we performed the HCS in neuroblastoma cells, and identified 14 miRNAs that significantly induce neurite outgrowth - the morphological differentiation marker neuroblastoma cells. We further examined the identified top 5 miRNAs in additional MYCN-nonamplified and MYCN-amplified neuroblastoma cells and identified miRNAs that have general effects in inducing neurite outgrowth in neuroblastoma cells with different MYCN genetic backgrounds. This fulfills the goal proposed in Aim 1. We also validated the identified top 5 miRNAs in inducing cell differentiation by examining the expression of molecular differentiation markers. This fulfills the partial task proposed in Aim 2. We further characterized the tumor suppressive function of miR-506-3p, the most potent novel differentiation-inducing miRNAs identified from the screen. Our results support the therapeutic potential of miR-506-3p mimic as a differentiation agent to treat neuroblastoma.

\section{Key Research Accomplishments}

\subsection{We identified novel microRNAs that are potent inducers of neuroblastoma cell differentiation.}

We developed a HCS approach to identify differentiation-inducing miRNA mimics based on quantification of
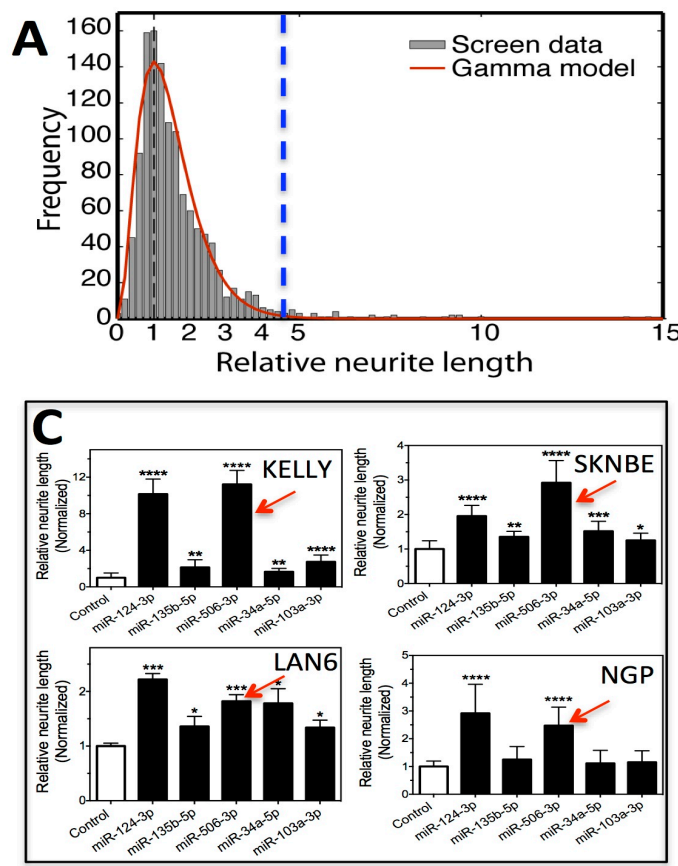

B
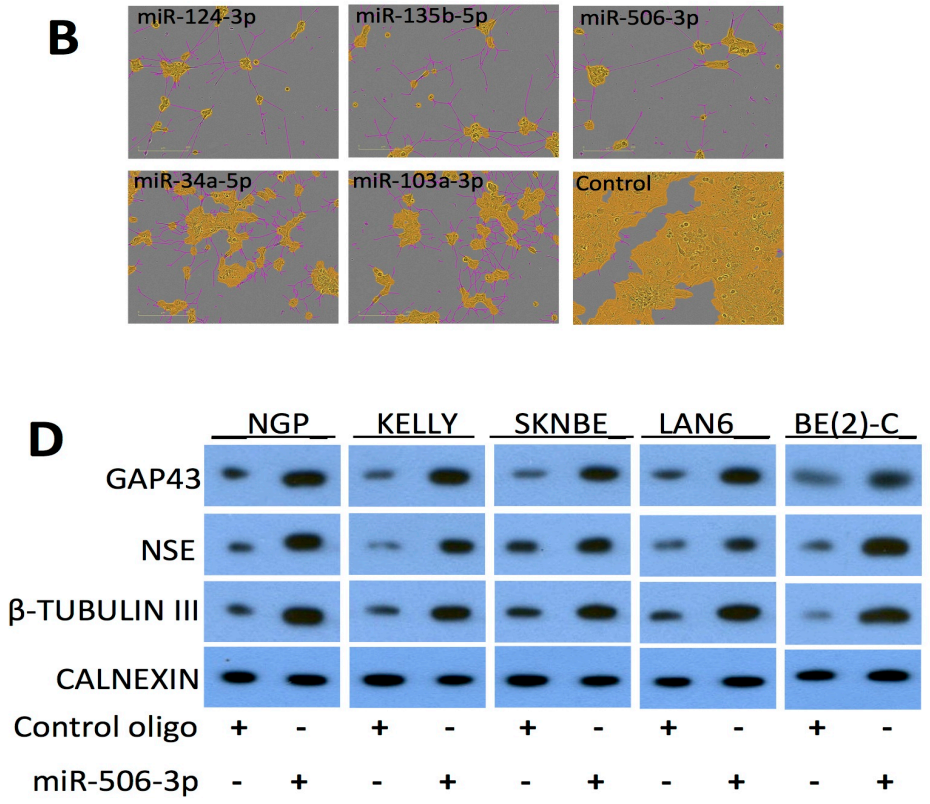

Figure 1: HCS identified novel differentiation-inducing miRNAs in neuroblastoma cells. A, HCS in neuroblastoma cell line BE(2)-C identifies miRNA mimics that induce neurite outgrowth more potently than RA. The distribution of post-normalized neurite length measurements (grey histogram) for individual miRNA mimics from the screen and the fitted Gamma distribution curve (red line, $\alpha=3.27$, $\beta=0.444)$ generated by the method described in our publication ${ }^{I}$. Blue line, effect of $5 \mu \mathrm{M}$ RA. B, Representative cell images, defined for cell body area (yellow) and neurites (pink), showing the effect of the identified top 5 miRNAs on neurite outgrowth. C, Effect of the identified top 5 miRNAs on neurite outgrowth in multiple cell lines. $(*, p<0.05 ; * *, p<0.01 ; * * *, p<0.001 ; * * * *, p<0.0001)$. D, Effects of miR-506-3p mimic on protein expression of differentiation markers (GAP43, NSE and B-TUBULIN III) in multiple cell lines, with CALNEXIN as a loading control. 
neurite outgrowth, the morphological marker of neuroblastoma cell differentiation ${ }^{l}$. As shown in Figure 1A, we identified miRNAs that have more potent effect than retinoic acid in inducing neurite outgrowth in neuroblastoma cell line BE(2)-C. Table 1 lists the identified 14 miRNAs that significantly induced neurite outgrowth. Several miRNAs that we identified from the screen were demonstrated to induce neuroblastoma cell differentiation previously (Table 1), further demonstrating the sensitivity of our screening approach. Cell images shown in Figure 1B indicates that the top 5 miRNAs induce dramatic neurite outgrowth comparing to untreated cells (control). As shown in Figure 1C, we further demonstrated that the identified top 5 miRNAs have general effect in inducing neurite outgrowth in neuroblastoma cell lines with different genetic backgrounds (Table 2). In addition, these 5 miRNAs induce expression of molecular differentiation markers ${ }^{2-5}$ (Figure 1D), indicating that cell differentiation is truly induced. Among these 5 miRNAs, miR-506-3p is the most potent novel differentiation-inducing miRNA that we identified from the screen.

Table 1. Fourteen miRNA mimics identified from HCS as inducing neurite outgrowth using a FDR threshold $<0.01$.

\begin{tabular}{lcccc}
\hline \multicolumn{1}{c}{ (a) miRNA } & $\begin{array}{c}\text { (b) Neurite length } \\
\text { (Mean } \pm \text { SD) }\end{array}$ & (c) $\boldsymbol{p}$ value & (d) FDR & (f) Ref \\
\hline hsa-miR-124-3p & $14.55 \pm 4.75$ & $1.11 \mathrm{E}-11$ & $1.37 \mathrm{E}-08$ & 8,15 \\
hsa-miR-135b-5p & $14.02 \pm 4.29$ & $3.26 \mathrm{E}-11$ & $2.02 \mathrm{E}-08$ & \\
hsa-miR-506-3p & $10.04 \pm 3.41$ & $1.05 \mathrm{E}-07$ & $4.34 \mathrm{E}-05$ & \\
hsa-miR-34a-5p & $9.49 \pm 3.18$ & $3.11 \mathrm{E}-07$ & $8.81 \mathrm{E}-05$ & \\
hsa-miR-103a-3p & $9.43 \pm 2.67$ & $3.56 \mathrm{E}-07$ & $8.81 \mathrm{E}-05$ & 11 \\
hsa-miR-450b-3p & $9.26 \pm 2.64$ & $4.94 \mathrm{E}-07$ & $1.02 \mathrm{E}-04$ & \\
hsa-miR-449a & $9.16 \pm 2.47$ & $6.03 \mathrm{E}-07$ & $1.07 \mathrm{E}-04$ & \\
hsa-miR-2110 & $9.00 \pm 2.40$ & $8.21 \mathrm{E}-07$ & $1.27 \mathrm{E}-04$ & \\
hsa-miR-34b-5p & $8.41 \pm 2.16$ & $2.66 \mathrm{E}-06$ & $3.66 \mathrm{E}-04$ & \\
hsa-miR-107 & $7.60 \pm 1.98$ & $1.27 \mathrm{E}-05$ & $1.55 \mathrm{E}-03$ & 10 \\
hsa-miR-3714 & $7.56 \pm 1.91$ & $1.37 \mathrm{E}-05$ & $1.55 \mathrm{E}-03$ & \\
hsa-miR-449b-5p & $7.40 \pm 1.85$ & $1.89 \mathrm{E}-05$ & $1.95 \mathrm{E}-03$ & \\
hsa-miR-137 & $7.03 \pm 1.36$ & $3.83 \mathrm{E}-05$ & $3.65 \mathrm{E}-03$ & 9 \\
hsa-miR-3937 & $6.93 \pm 1.05$ & $4.61 \mathrm{E}-05$ & $4.08 \mathrm{E}-03$ & \\
\hline
\end{tabular}

Table 2. Genetic backgrounds of neuroblastoma cell lines used in the study

\begin{tabular}{lcccccc}
\hline Cell line & Age & Gender & Stage & $\begin{array}{c}\text { Chr 1p } \\
\text { alteration }\end{array}$ & $\begin{array}{c}\text { Chr 17 } \\
\text { alteration }\end{array}$ & MYCN ampl. \\
\hline BE(2)-C & 2 & male & 4 & $\mathrm{Y}$ & $\mathrm{N}$ & $\mathrm{Y}$ \\
SK-N-BE & 1.8 & male & 4 & $\mathrm{Y}$ & $\mathrm{N}$ & $\mathrm{Y}$ \\
LAN6 & 5.8 & male & 4 & $\mathrm{~N}$ & unk & $\mathrm{N}$ \\
NGP & 2.6 & male & unk & Y & Y & Y \\
KELLY & unk & unk & unk & unk & unk & Y \\
\hline
\end{tabular}

Shown are the cell line names, ages and genders of the patients, stages of the tumor from which the cell lines are derived, chromosome $1 \mathrm{p}$ and 17 alterations, and MYCN gene amplification status. *unk, unknown; Chr, Chromosome; ampl., amplification.

4.2. miR-506-3p mimic shows potent effect in inhibiting neuroblastoma cell survival and growth, strongly suggesting the potential of developing miR-506-3p mimic-based differentiation agents for treating neuroblastoma.

We compared the effect of miR-506-3p on neuroblastoma cell survival with retinoic acid as well as other tumor suppressive miRNAs that were previously identified in neuroblastoma cells ${ }^{2,6-14}$. Remarkably, our results 
indicate that miR-506-3p shows much more potent effect on reducing cell survival than RA (Figure 2A) and than other examined miRNAs (Figure 2B). We further show that miR-506-3p mimic significantly reduce the ability of neuroblastoma cells to form colonies, indicating their long-term capacity to inhibit cell proliferation (Figure 2C-D). Altogether, these results support that miR-506-3p mimic has highest therapeutic potential to be applied as a differentiation agent to treat neuroblastoma among the tumor suppressive miRNAs identified in neuroblastoma cells.
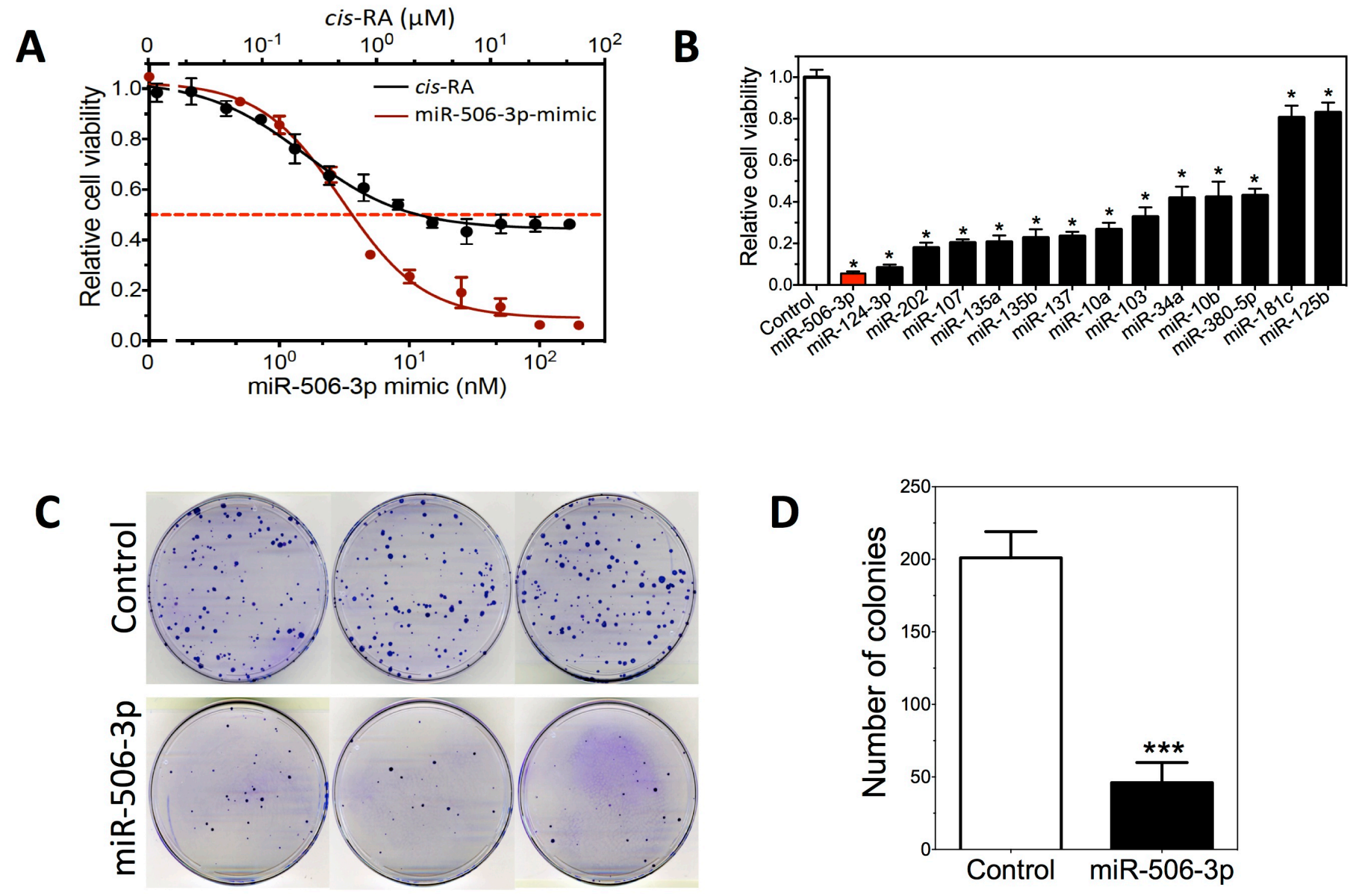

Figure 2: Characterization of the tumor suppressive function of miR-506-3p mimic in neuroblastoma cells. A, Dose-dependent effect of miR-506-3p mimic and RA on cell viability in BE(2)-C cells. Cell viability was measured after transfection with miR-506-3p mimic for 4 days or treated with RA for 5 days. B, Effect of different miRNAs on BE(2)-C cell survival. Cells were transfected with 25 $\mathrm{nM}$ miRNA mimics or control, and cell viability was measured after 5 days. $\left({ }^{*}, p<0.05\right)$. C-D, Colony formation assay as a function of miR-506-3p mimic. BE(2)-C cells were transfected with the $25 \mathrm{nM}$ of miR-506-3p mimic or control oligo and cultured overnight. 500 cells were re-plated in $10 \mathrm{~cm}$ dishes. After 14 days, colonies were visualized by staining with $1 \%$ crystal violet. The number of colonies were analyzed using Image J. Shown are (C) plate images of colony formation and (D) quantified colony numbers in each treatment group.

\section{Conclusion and future plans}

In summary, we have identified differentiation-inducing miRNA mimics that have potential to be developed into novel differentiation agents for treating neuroblastoma. Since these miRNA mimics has general effect in neuroblastoma cells with different genetic backgrounds, they hold the promise to treat neuroblastoma that are resistant to current differentiation agents. In the next budget period, we will perform the validation of the rest 9 differentiation-inducing miRNAs by examining their function in inducing expression of differentiation markers and cell growth arrest in multiple neuroblastoma cell lines with different genetic backgrounds - this will fulfill the objectives and overall goal of the proposed study.

\section{Publications, Abstracts and Presentations}

\subsection{Publications}

1. Zhao Z, Ma X, Li M, Kosti A, Lin G, Hsiao TH, Chen Y, Pertsemlidis A and *Du L. A high-content 
morphological screen identifies novel microRNAs that regulate neuroblastoma cell differentiation. Molecular Cancer, Under review. *, Corresponding author.

2. Zhao Z, Ma X, Hsiao TH, Lin G, Kosti A, Yu X, Suresh U, Chen Y, Tomlinson G, Pertsemlidis A and *Du L. A high-content morphological screen identifies novel microRNAs that regulate neuroblastoma cell differentiation. Oncotarget. 2014; 5(9): 2499-512. *, Corresponding author.

\subsection{Abstracts}

1. Li M, Ma X, Pertsemlidis A and Du L. MYCN regulates the response of neuroblastoma cells to differentiation-inducing microRNAs. The University of Texas Health Science Center 2014 Summer research Program. San Antonio, TX. August 5, 2014.

2. Zhao Z, Ma X, Hsiao TH, Lin G, Kosti A, Yu X, Suresh U, Chen Y, Tomlinson GE, Pertsemlidis A, Du L. A functional screen identifies novel microRNAs that induce neuroblastoma cell differentiation. First Annual San Antonio Conference on Stem Cell Research \& Regenerative Medicine. San Antonio. February 13-14, 2014.

\subsection{Presentations}

1. Targeting the differentiation pathway in neuroblastoma differentiation therapy. 2014 Cancer Therapy and Research Center Annual Symposium, University of Texas Health Science Center at San Antonio. San Antonio, TX, September 26, 2014.

2. Targeting the differentiation pathway in neuroblastoma differentiation therapy. Pediatric Translational Working Group, Cancer Therapy and Research Center, University of Texas Health Science Center at San Antonio. San Antonio, TX, July 29, 2014.

3. Cell differentiation in neuroblastoma. Department of Comparative Biomedical Sciences, School of Veterinary Medicine, Louisiana State University. Baton Rouge, LA. April 16, 2014.

\section{Inventions, Patents and Licenses}

A patent application entitled "microRNA mimics as potential differentiation agents for treating neuroblastoma" has been submitted to US Patent and Trademark Office through the Office of Technology Transfer and Commercialization at UT Health Science Center at San Antonio.

(OTTC Reference Number: 2014.020.HSCS; Serial Number: 61/939,730)

\section{Reportable Outcome}

7.1. We developed a HCS approach for identifying differentiation-inducing agents in neuroblastoma cells. This approach can be applied to identify novel differentiation agents for treating neuroblastoma from other sources of anti-cancer drugs, such natural products.

7.2. We identified novel differentiation-inducing miRNA mimics. These miRNA mimics are potential candidates for developing novel and more efficacious differentiation agents for treating neuroblastoma, which holds the promise to significantly improve the survival and health of neuroblastoma patients.

\section{Other Achievements}

Based on the work supported by this award, I submitted the following grant applications:

1) NIH/NCI (1R01CA194182-01) (R01) (L. Du) 04/01/2015-03/31/2020 6 Cal. mos. (\$1250,000 direct $\$$ 1853,900 total)

\section{Therapeutic mechanisms of differentiation-inducing microRNAs in neuroblastoma}

Goal: To define the role of microRNAs in regulating neuroblastoma cell differentiation, and to develop miRNA-based differentiation agents for treating neuroblastoma.

Role: Principal Investigator

2) DoD PRCRP Career Development Award (L.Du) ０7/01/2015-06/30/2018 3.0 Cal. mos. (\$360,000 direct $/ \$ 538,200$ total) 
Role of miR-506-3p in neuroblastoma cell differentiation and differentiation therapy

Goal: To elucidate the mechanisms underlying the differentiation-inducing function of microRNA miR506-3p, and to develop novel miR-506-3p-based therapeutic agents to treat neuroblastoma.

Role: Principal Investigator

\section{References}

1. Zhao, Z., Ma, X., Hsiao, T. H., Lin, G., Kosti, A., Yu, X., Suresh, U., Chen, Y., Tomlinson, G. E., Pertsemlidis, A., and Du, L. (2014) A high-content morphological screen identifies novel microRNAs that regulate neuroblastoma cell differentiation, Oncotarget 5, 2499-2512.

2. Foley, N. H., Bray, I., Watters, K. M., Das, S., Bryan, K., Bernas, T., Prehn, J. H., and Stallings, R. L. (2011) MicroRNAs $10 \mathrm{a}$ and $10 \mathrm{~b}$ are potent inducers of neuroblastoma cell differentiation through targeting of nuclear receptor corepressor 2, Cell Death Differ 18, 1089-1098.

3. Takenobu, H., Shimozato, O., Nakamura, T., Ochiai, H., Yamaguchi, Y., Ohira, M., Nakagawara, A., and Kamijo, T. (2011) CD133 suppresses neuroblastoma cell differentiation via signal pathway modification, Oncogene 30, 97-105.

4. Cheung, Y. T., Lau, W. K., Yu, M. S., Lai, C. S., Yeung, S. C., So, K. F., and Chang, R. C. (2009) Effects of all-trans-retinoic acid on human SH-SY5Y neuroblastoma as in vitro model in neurotoxicity research, Neurotoxicology 30, 127-135.

5. Mao, L., Ding, J., Zha, Y., Yang, L., McCarthy, B. A., King, W., Cui, H., and Ding, H. F. (2011) HOXC9 links cell-cycle exit and neuronal differentiation and is a prognostic marker in neuroblastoma, Cancer Res 71, 4314-4324.

6. Le, M. T., Xie, H., Zhou, B., Chia, P. H., Rizk, P., Um, M., Udolph, G., Yang, H., Lim, B., and Lodish, H. F. (2009) MicroRNA-125b promotes neuronal differentiation in human cells by repressing multiple targets, Mol Cell Biol 29, 5290-5305.

7. Swarbrick, A., Woods, S. L., Shaw, A., Balakrishnan, A., Phua, Y., Nguyen, A., Chanthery, Y., Lim, L., Ashton, L. J., Judson, R. L., Huskey, N., Blelloch, R., Haber, M., Norris, M. D., Lengyel, P., Hackett, C. S., Preiss, T., Chetcuti, A., Sullivan, C. S., Marcusson, E. G., Weiss, W., L'Etoile, N., and Goga, A. (2010) miR-380-5p represses p53 to control cellular survival and is associated with poor outcome in MYCN-amplified neuroblastoma, Nat Med 16, 1134-1140.

8. Makeyev, E. V., Zhang, J., Carrasco, M. A., and Maniatis, T. (2007) The MicroRNA miR-124 promotes neuronal differentiation by triggering brain-specific alternative pre-mRNA splicing, Mol Cell 27, 435448.

9. Bier, A., Giladi, N., Kronfeld, N., Lee, H. K., Cazacu, S., Finniss, S., Xiang, C., Poisson, L., de Carvalho, A. C., Slavin, S., Jacoby, E., Yalon, M., Toren, A., Mikkelsen, T., and Brodie, C. (2013) MicroRNA-137 is downregulated in glioblastoma and inhibits the stemness of glioma stem cells by targeting RTVP-1, Oncotarget 4, 665-676.

10. Smith, B., Treadwell, J., Zhang, D., Ly, D., McKinnell, I., Walker, P. R., and Sikorska, M. (2010) Largescale expression analysis reveals distinct microRNA profiles at different stages of human neurodevelopment, PLoS One 5, e11109.

11. Annibali, D., Gioia, U., Savino, M., Laneve, P., Caffarelli, E., and Nasi, S. (2012) A new module in neural differentiation control: two microRNAs upregulated by retinoic acid, miR-9 and -103, target the differentiation inhibitor ID2, PLoS One 7, e40269.

12. Cole, K. A., Attiyeh, E. F., Mosse, Y. P., Laquaglia, M. J., Diskin, S. J., Brodeur, G. M., and Maris, J. M. (2008) A functional screen identifies miR-34a as a candidate neuroblastoma tumor suppressor gene, Molecular cancer research : MCR 6, 735-742.

13. Li, Y., Wang, H., Li, J., and Yue, W. (2014) MiR-181c modulates the proliferation, migration, and invasion of neuroblastoma cells by targeting Smad7, Acta biochimica et biophysica Sinica 46, 48-55.

14. Li, Y. G., He, J. H., Yu, L., Hang, Z. P., Li, W., Shun, W. H., and Huang, G. X. (2014) microRNA202 suppresses MYCN expression under the control of E2F1 in the neuroblastoma cell line LAN5, Molecular medicine reports 9, 541-546. 
15. Silber J, Lim DA, Petritsch C, Persson AI, Maunakea AK, Yu M, Vandenberg SR, Ginzinger DG, James CD, Costello JF, Bergers G, Weiss WA, Alvarez-Buylla A, et al. miR- 124 and miR-137 inhibit proliferation of glioblastoma multiforme cells and induce differentiation of brain tumor stem cells. BMC Med 2008;6:14.

\section{Appendices}

Please see the attached (1) Patent Application Form and (2) research paper published in Oncotarget in 2014. 
This form is used to report a discovery, invention, or other intellectual property made by faculty members, fellows, staff members, or students, within the course and scope of employment or resulting from activities performed on U.T. System time, or with the support of State funds, or from using facilities or resources owned by the U.T. System or any of its institutions ("Inventors"). Inventors are bound by the Rules and Regulations of the Board of Regents of the University of Texas System and, by signing this IDF, the Inventors acknowledge (1) the Regents' intellectual property rights and (2) that all right, title, and interest in the discovery, invention, or other intellectual property is assigned and transferred to the Regents immediately upon creation, origination or acquisition of same and (3) that Inventors are additionally bound by the intellectual property policy of their U.T. institution. An IDF can be filed at any time and at any stage of a research program.

\section{INVENTOR INFORMATION}

Names of Inventors. List the corresponding inventor first. The corresponding inventor will be the point-of-contact between the inventor(s) and OTTC. Return this document as an attachment to an email addressed to disclosures@uthscsa.edu. Signed hard-copy originals should be mailed to:

Office of Technology Transfer and Commercialization, 8403 Floyd Curl Dr., Mail Stop 7746, San Antonio TX, 78229

1. Corresponding Inventor What is your percent (\%) contribution to this disclosed 70 invention?

\begin{tabular}{lcc}
\hline $\begin{array}{l}\text { NAME } \\
\text { Liqin Du }\end{array}$ & $\begin{array}{c}\text { TITLE } \\
\text { Assistant Professor/Research }\end{array}$ \\
\hline DEPARTMENT & TELEPHONE & EMAIL ADDRESS \\
Cellular and Structural Biology & $(210)$ dul2@uthsCSa.edu \\
\hline CITIZENSHIP & HOME ADDRESS 9112 & \\
P.R. China & 8906 Breezefield. San Antonio, TX 78240 &
\end{tabular}

LIST ADDITIONAL INSTITUTIONAL AFFILIATION(S)

GCCR I

Do you have a Veterans Administration (VA) appointment?

Is your VA appointment without compensation

(WOC)?

If you have answered Yes to either of the above Questions, fill out the VA Affiliation Questionnaire at the end of this form.

Signature

2. Inventor

What is your percent (\%) contribution to this disclosed

invention?

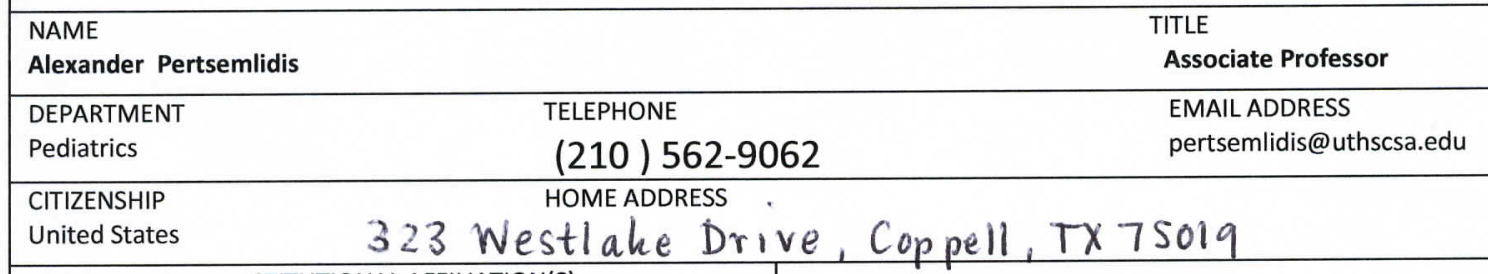

LIST ADDITIONAL INSTITUTIONAL AFFILIATION(S)

GCCR I

Do you have a Veterans Administration (VA) appointment?

Is your VA appointment without compensation (WOC)?

If you have answered Yes to either of the above Questions, fill out the VA Affiliation Questionnaire at the end of this form.

Signature Hecoude Pentsene Date (mm/dd/yyyy)

Return this form by email to disclosures@uthscsa.edu

Mail Originals to: Office of Technology Transfer and Commercialization, 8403 Floyd Curl Drive, Mail Stop 7746, San Antonio, TX 78229 Document ID: ottc_idf_form0a_revised20130708.docx

Last saved on 2/20/2014 2:05 PM

Page 1 of 8 


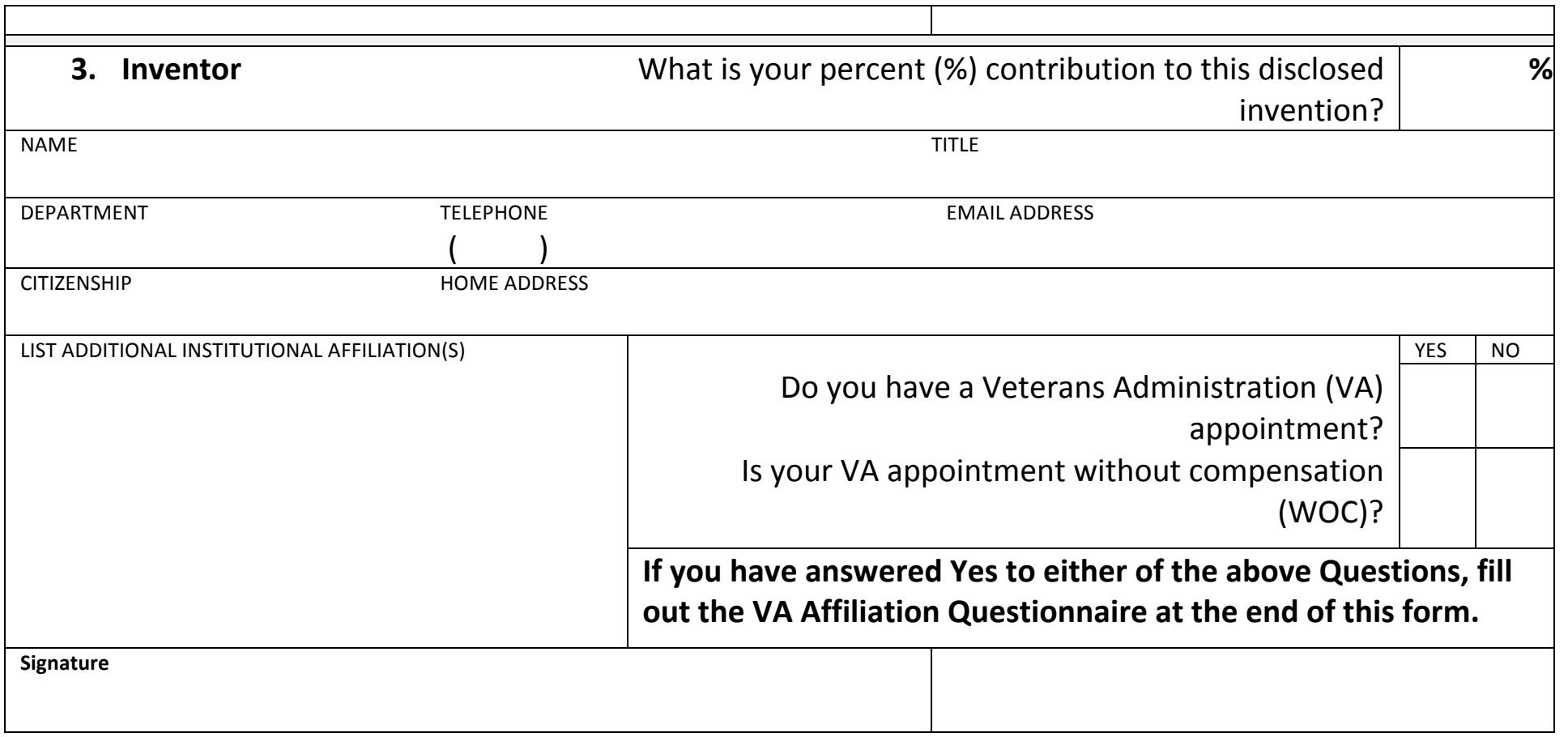

\section{**ATTACH ADDITIONAL INVENTOR INFORMATION SHEETS AS NECESSARY **}

\section{INVENTION}

The US Patent and Trademark Office, http://www.uspto.gov, defines an invention as any new and useful process, machine, manufacture, or composition of matter, or any new and useful improvement thereof, which, taken together, include practically everything that is made by man.

A. Invention Title. Provide a non-confidential title that is brief and broadly descriptive. Describe what the invention can do, not how it does it.

microRNA mimics as potential differentiation agents for treating neuroblastoma

B. Abstract. Provide a non-confidential abstract. Summary results and data may be included, but materials and methods should be omitted.

Neuroblastoma, the most common extracranial solid tumor of childhood, arises from neural crest cell precursors that fail to differentiate. Inducing cell differentiation is an important therapeutic strategy for neuroblastoma. We developed a direct functional high-content screen to identify differentiationinducing microRNAs, in order to develop microRNA-based differentiation therapy for neuroblastoma. We discovered novel microRNAs, and more strikingly, three microRNA seed families that induce neuroblastoma cell differentiation. In addition, we showed that microRNA seed families were overrepresented in the identified group of fourteen differentiation-inducing microRNAs, suggesting that microRNA seed families are functionally more important in neuroblastoma differentiation than microRNAs with unique sequences. We further investigated the differentiation-inducing function of the microRNA-506-3p/microRNA-124-3p seed family, which was the most potent inducer of differentiation. We showed that the differentiation-inducing function of microRNA-506-3p/microRNA124-3p is mediated, at least partially, by down-regulating expression of their targets CDK4 and STAT3. We further showed that expression of miR-506-3p, but not miR-124-3p, is dramatically upregulated in differentiated neuroblastoma cells, suggesting the important role of endogenous miR-506-3p in 
differentiation and tumorigenesis. Overall, our functional screen on microRNAs provided the first comprehensive analysis of the involvement of microRNA species in neuroblastoma cell differentiation and identified novel differentiation-inducing microRNAs. Further investigations are certainly warranted to fully characterize the function of the identified microRNAs in order to eventually improve neuroblastoma therapy.

C. Key words. An abstract of the invention may be posted online in a searchable database. Provide key words that will help interested parties find the invention.

Neuroblastoma, microRNA, High-content screen, Differentiation, Differentiation therapy

D. Confidential Description of the Invention. Describe the invention completely. Include sketches, drawings, and photographs as appropriate. Provide key data and experimental results. If available, attach a draft manuscript.

Please refer to the manuscript.

E. Evidence for Patentability. The criteria for a US patent are novelty, non-obviousness, and utility. Indicate below evidence for each criterion.

1. NOVELTY. How does the invention improve what has already been described in the scientific or patent literature? Attach copies of key publications (including your own), patents, and patent applications that demonstrate the progression of technology that led to your invention, as well as the features of your invention that improve on the state-of-the-art.

The identified differentiation-inducing microRNAs have not been reported before.

Return this form by email to disclosures@uthscsa.edu

Mail Originals to: Office of Technology Transfer and Commercialization, 8403 Floyd Curl Drive, Mail Stop 7746, San Antonio, TX 78229

Document ID: ottc_idf_form0a_revised20130708.docx

Last saved on 2/20/2014 2:05 PM

Page 3 of 8 
2. NON-OBVIOUSNESS. What makes your invention new and unexpected? Why was your invention not obvious, at the time the invention was made, to a person skilled in the art?

We identified microRNAs that has not been reported to induce neuroblastoma cell differentiation. The invention not obvious because that, based on current knowledge, it cannot be predicted to induce neuroblastoma cell differentiation.

3. UTILITY. What problem does the invention solve? How does the invention fit into current practice, use, diagnosis or therapy? Who might find the invention useful, and be willing to pay for it, and why?

The invention potentially provides novel and more potent therapeutic agents for neuroblastoma therapy. Companies that develop anti-cancer drugs, especially those with an interest on microRNA delivery, might find it useful.

F. Stage of Development. Provide evidence for the conception of the invention including the date, such as copies of original notebook pages, reports, charts, notes, and electronic media. Ensure that original records are signed, dated, and witnessed and kept in a secure location. To what extent has the invention been reduced to practice? Has the invention been sufficiently tested to demonstrate that it will work for its intended purpose? Attach data. What further work is needed to develop the invention?

Animal studies need to be done to further evaluate the therapeutic value of the identified microRNA mimics.

G. Commercialization. What companies might be interested in manufacturing or selling the invention, and why? Do you have personal contacts with such companies? If so, provide contact information. Does other technology provide similar utility? If so, what practical or competitive advantage does the invention offer?

Mirna Therapeutics, Inc. This company is developing microRNA-based therapeutic approaches for treating cancer. 


\section{PUBLIC DISCLOSURE}

Public disclosure prior to filing a patent application (a presentation, a published paper, a web publication or abstract, or an offer for sale) may compromise patent rights. After public disclosure, US patent law provides a one-year grace period in which to file but essentially all foreign rights are lost. Inventors are urged to use discretion, take advantage of Confidential Disclosure Agreements and submit IDFs well in advance of presentations or publications. Please contact OTTC for assistance.

A. Has the invention been disclosed in an abstract, paper, grant application, talk, news story, thesis, or public conversation? If YES, please list with details and enclose copies, if available.

Zhao Z, Ma X, Hsiao TH, Lin G, Kosti A, Yu X, Suresh U, Chen Y, Tomlinson GE, Pertsemlidis A, Du L. A functional screen identifies novel microRNAs that induce neuroblastoma cell differentiation. First Annual San Antonio Conference on Stem Cell Research \& Regenerative Medicine. San Antonio. February 13-14, 2014.

B. Is a publication or other disclosure planned in the next six months? If YES, please list $\mathrm{X}$ with details and enclose copies, if available.

Zhao Z, Ma X, Hsiao TH, Lin G, Kosti A, Yu X, Suresh U, Chen Y, Tomlinson G, Pertsemlidis

$A$ and *Du L. A high-content morphological screen identifies novel microRNAs that regulate neuroblastoma cell differentiation. Oncotarget, accepted, 2014.

C. Have you spoken about the invention to persons outside the university? If YES, please

describe the circumstances, dates, and extent of the disclosure.

\begin{tabular}{|l|l|}
\hline YES & NO \\
\hline & $\mathrm{X}$ \\
\hline
\end{tabular}

D. Have technical materials or items related to the invention such as chemical compounds, reagents, antibodies, biologicals, cell lines, chips, or software, ever been sent to or received from another organization? If YES, provide details (what was transferred, date, and the originating or receiving organization).

The microRNA mimics initially used in the original screen were purchased from Dharamcon Inc. Subsequent validation was performed using microRNA mimics synthetized by Integrated 
DNA technologies.

E. In reference to SECTION III. Item D. above, were the materials transferred under a \begin{tabular}{|l|l|}
\hline YES & NO \\
\hline & $\mathrm{X}$
\end{tabular} Materials Transfer Agreement (MTA)? If YES, please attach a copy.

\section{SPONSORSHIP}

Sponsors often have certain rights to inventions discovered through funded research.

** DO NOT leave this section blank. If there were no sponsors, please clearly indicate this. **

A. Government Agency Contract? If YES, then indicate Funding Agency/Grant Number / Title / $\quad$ X Principal Investigator (PI)

Funding Agency and Grant Number

Department of Defense

PRMRP Grant\# PR121532

Identifying microRNAs that regulate neuroblastoma
cell differentiation

B. CPRIT Grant? If YES, then indicate Grant Number / Title / Principal Investigator (PI)

What proportion of this invention was funded by your CPRIT grant?

C. Other Sponsoring Entity. Please give name(s) of the company, university, foundation, I/UCRC, or other sponsor(s) and the university account number and effective date(s). If the invention was made under a Sponsored Research Agreement, please attach a copy.

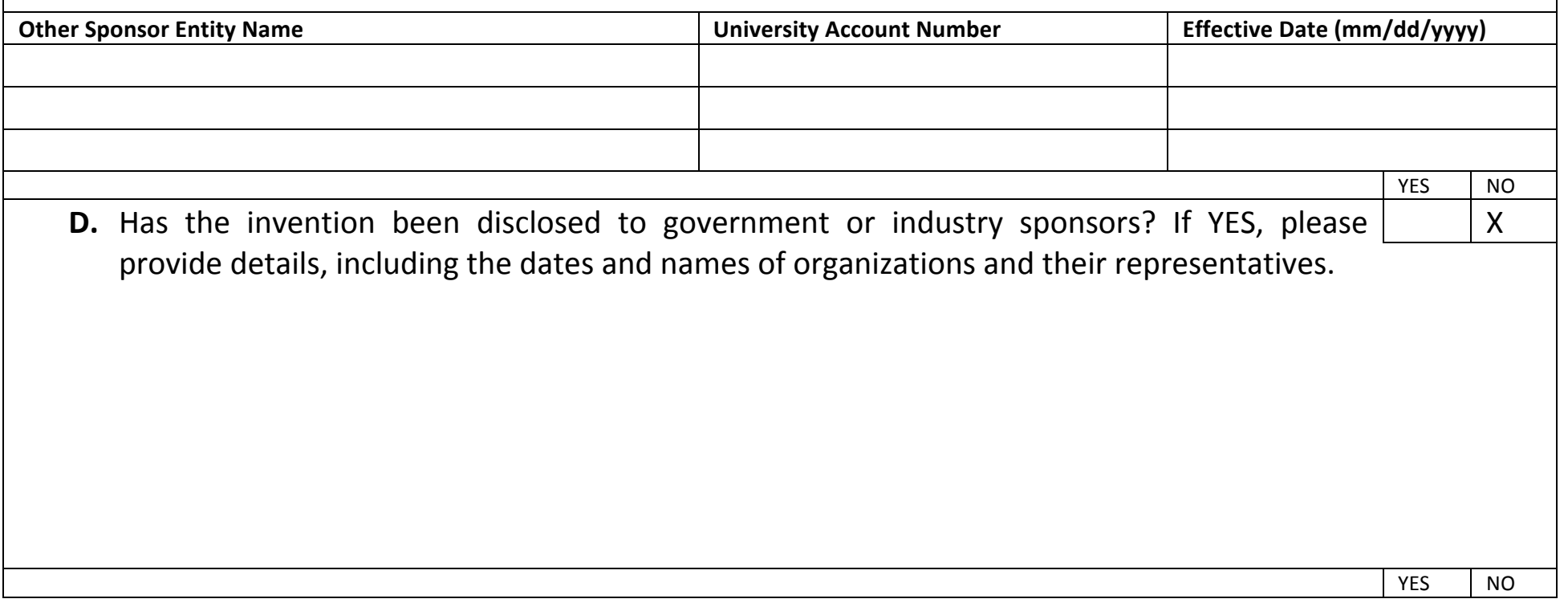


OFFICE OF TECHNOLOGY TRANSFER AND COMMERCIALIZATION (OTTC) INVENTION DISCLOSURE FORM (IDF)

E. During the past three (3) years have any of the Inventors had a consulting agreement $\mathrm{X}$ related in any way to the field of the invention or with the sponsor of the research? If YES, please provide details, including a copy of the consulting contract and statement of work.

F. Conflict of Interest. Have all the Inventors filed annual Conflict of Interest (COI) disclosures or amendments, for the current financial year as required by university policy? 


\section{VA Affiliation Questionnaire}

Name:

1. Do you receive any portion of your salary from the VA? YES ___ NO_

a. If yes, what percentage of your salary is paid by VA? __ $\%$

2. The invention was made:

a. During my official VA Working Hours

b. With a contribution by the VA of:

YES__ NO__
i. Facilities
YES
$\mathrm{NO} \_\mathrm{X}$
ii. Equipment
YES
$\mathrm{NO} \_\mathrm{X}$
iii. Materials
YES
$\mathrm{NO} \_$X
iv. Funds
YES
$\mathrm{NO} \_\mathrm{X}$
v. Information
YES
NO_ $\mathrm{X}$

vi. Time or services of other VA employees on official duty

YES

NO_ $\mathrm{X}$

3. The Invention:
a. Bears a direct relation to my VA research duties
YES
$\mathrm{NO} \_\mathrm{X}$
b. Was made in consequence of my VA research duties
YES
$\mathrm{NO} \_\mathrm{X}$

List of VA Approved Research Projects (research projects that have been evaluated and approved by the VA Research and Development Committee) I am working on:

Additional Information:

Return this form by email to disclosures@uthscsa.edu

Mail Originals to: Office of Technology Transfer and Commercialization, 8403 Floyd Curl Drive, Mail Stop 7746, San Antonio, TX 78229

Document ID: ottc_idf_form0a_revised20130708.docx

Last saved on 2/20/2014 2:05 PM

Page 8 of 8 


\title{
A high-content morphological screen identifies novel microRNAs that regulate neuroblastoma cell differentiation
}

\author{
Zhenze Zhao' ${ }^{1}$, Xiuye Ma ${ }^{1}$, Tzu-Hung Hsiao ${ }^{1}$, Gregory Lin ${ }^{1}$, Adam Kosti ${ }^{1}$, Xiaojie Yu ${ }^{2}$, \\ Uthra Suresh $^{1}$, Yidong Chen ${ }^{1,3}$, Gail E. Tomlinson ${ }^{1,4}$, Alexander Pertsemlidis ${ }^{1,4,5}$, \\ Liqin Du ${ }^{1,5}$ \\ ${ }^{1}$ Greehey Children's Cancer Research Institute, UT Health Science Center at San Antonio, TX \\ ${ }^{2}$ Graduate School of Biomedical Sciences, UT Health Science Center at San Antonio, TX \\ ${ }^{3}$ Department of Epidemiology and Biostatistics, UT Health Science Center at San Antonio, TX \\ ${ }^{4}$ Department of Pediatrics, UT Health Science Center at San Antonio, TX \\ ${ }^{5}$ Department of Cellular and Structural Biology, UT Health Science Center at San Antonio, TX \\ Correspondence to: Liqin Du, email: dul2@uthscsa.edu \\ Keywords: neuroblastoma, microRNA, high-content screen, differentiation, differentiation therapy \\ Received: December 14, 2013 Accepted: February 27, $2014 \quad$ Published: February 28, 2014
}

This is an open-access article distributed under the terms of the Creative Commons Attribution License, which permits unrestricted use, distribution, and reproduction in any medium, provided the original author and source are credited.

\section{ABSTRACT:}

Neuroblastoma, the most common extracranial solid tumor of childhood, arises from neural crest cell precursors that fail to differentiate. Inducing cell differentiation is an important therapeutic strategy for neuroblastoma. We developed a direct functional high-content screen to identify differentiation-inducing microRNAs, in order to develop microRNA-based differentiation therapy for neuroblastoma. We discovered novel microRNAs, and more strikingly, three microRNA seed families that induce neuroblastoma cell differentiation. In addition, we showed that microRNA seed families were overrepresented in the identified group of fourteen differentiationinducing microRNAs, suggesting that microRNA seed families are functionally more important in neuroblastoma differentiation than microRNAs with unique sequences. We further investigated the differentiation-inducing function of the microRNA-506-3p/ microRNA-124-3p seed family, which was the most potent inducer of differentiation. We showed that the differentiation-inducing function of microRNA-506-3p/microRNA124-3p is mediated, at least partially, by down-regulating expression of their targets CDK4 and STAT3. We further showed that expression of miR-506-3p, but not miR124-3p, is dramatically upregulated in differentiated neuroblastoma cells, suggesting the important role of endogenous miR-506-3p in differentiation and tumorigenesis. Overall, our functional screen on microRNAs provided the first comprehensive analysis on the involvements of microRNA species in neuroblastoma cell differentiation and identified novel differentiation-inducing microRNAs. Further investigations are certainly warranted to fully characterize the function of the identified microRNAs in order to eventually benefit neuroblastoma therapy.

\section{INTRODUCTION}

Neuroblastoma is the most common solid tumor of infancy and the most common extracranial solid tumor of childhood, accounting for more than $7 \%$ of childhood cancers and $15 \%$ of cancer-related childhood deaths $[1,2]$. Neuroblastoma arises from the neural crest cell precursors of the sympathetic nervous system that fail to differentiate
$[2,3]$ - this provides the basis for differentiation therapy, an approach to induce malignant cells to differentiate into mature cells, thereby leading to cell growth arrest and apoptosis [2, 4-6]. However, only a limited number of differentiation agents have been successfully used to treat neuroblastoma. The differentiation agent 13-cisretinoic acid (RA) is currently the standard of care for post-remission maintenance therapy in high-risk 
neuroblastoma [2]. Although such treatment has resulted in a significant increase in patient survival, more than $50 \%$ of the treated patients still develop recurrence [7, 8]. Such poor outcomes demand the development of new differentiation agents. Unfortunately, the mechanisms that result in the loss of differentiation ability of neuroblastoma cells are poorly understood, which poses an obstacle to such development. Therefore, identifying additional differentiation agents largely relies on the discovery of new targetable biological molecules that play critical roles in neuroblastoma differentiation.

High-throughput screening approaches significantly facilitate the discovery of novel anti-cancer drugs and drug targets. More recently, high-content screens (HCSs) based on automated cell imaging have been developed. However, current HCSs generally either use genetic engineered cell lines expressing fluorescent signals or involve staining of fixed cells $[9,10]$, which are generally time-consuming and consequently limit their broad applications to drug discoveries. We aim to develop a non-fluorescence, live-cell based HCS approach for identifying neuroblastoma differentiation-inducing agents. Neurite outgrowth, which is easily detectable under the microscope, is a well-recognized morphological differentiation marker of neuroblastoma cells in vitro [1114]. While undifferentiated cells usually show no visible neurites, fully differentiated neuroblastoma cells form neurites that are four to five times the length of the cell body. This differentiation trait facilitates the design of a functional HCS assay to directly identify substances that induce neuroblastoma cell differentiation. In this study, we developed such an approach and applied it in a screen for microRNAs (miRNAs) that induce differentiation.

miRNAs are endogenously expressed small RNAs that play a critical role in tumorigenesis [15-19]. The therapeutic potential of either exogenously increasing cellular miRNAs levels with synthetic miRNA mimics, or inactivating endogenous miRNAs with synthetic miRNA inhibitors has been demonstrated in previous studies [2022]. The role of miRNAs in neuroblastoma differentiation and tumorigenesis has been implicated[23-31], which suggests the potential of developing novel miRNAtargeting approaches to neuroblastoma differentiation therapy[32], and warrants a comprehensive understanding of the involvement of miRNAs in neuroblastoma cell differentiation. However, there has been no concerted effort to comprehensively investigate the functions of the miRNA species in neuroblastoma differentiation. By applying the HCS that we developed, we investigated the recently identified human miRNAs and identified differentiation-inducing miRNAs that have not been discovered previously.

\section{RESULTS}

\section{A HCS approach for measuring neuroblastoma cell differentiation is developed based on neurite quantification.}

Neurite outgrowth is well recognized as a morphological hallmark of neuroblastoma cell differentiation in vitro [11-14]. This facilitates the development of a HCS approach to identify differentiation-inducing agents based on quantification of neurite outgrowth. Neuroblastoma cell line BE(2)-C shows easily detectable neurite outgrowth upon induced differentiation by all-trans retinoic acid (ATRA). As shown in Figure 1A, ATRA (b) induces dramatic neurite outgrowth in BE(2)-C compared to control (a), and the neurites and cell body area can be clearly defined (c, d). Quantification (Figure 1B) shows that ATRA significantly increases the relative neurite length compared to control. In addition, ATRA induces neurite elongation in both timeand dose-dependent manners (Figure 1C-D and Suppl. Figure 1). Correspondingly, ATRA decreases cell viability (Figure 1E), stimulates expression of neuroblastoma differentiation markers (i.e., growth associated protein 43 (GAP43), neuron specific enolase (NSE) and $\beta$-TUBULIN III) [33-35], inhibits expression of cell proliferation markers (i.e., PCNA and Ki67), and increases expression of apoptosis markers (i.e., cleaved CASPASE 3 and PARP) (Figure 1F) in dose-dependent manners. These results indicate that neurite length is a reliable quantitative marker of $\mathrm{BE}(2)-\mathrm{C}$ cell differentiation, and therefore can be used to compare the efficacy of differentiation-inducing agents. This was the basis of our HCS protocol (Suppl. Figure 2) for identifying novel differentiation-inducing miRNAs.

\section{HCS identifies novel miRNAs that induce neuroblastoma cell differentiation.}

Using our HCS protocol, we screened a library of miRNA mimics (Dharmacon) in BE(2)-C cells. Figure 2A shows the neurite length distribution (grey histogram) associated with individual miRNA mimics. Replicate screens for one library plate from two independent transfections show that the results are highly reproducible (Figure $2 \mathrm{~B})(\mathrm{R}=0.95, p<0.0001)$, supporting the reliability of the screen. As shown in Figure 2A, the neurite length distribution following treatment with miRNA mimics is asymmetric; a small number of miRNAs are identified as dramatically increasing neurite lengths on the far right side of the distribution. In order to examine the neurite length distribution of unaffected cells, 13 plates of untreated $\mathrm{BE}(2)-\mathrm{C}$ cells were measured (Figure 2C). Kolmogorov- 
A

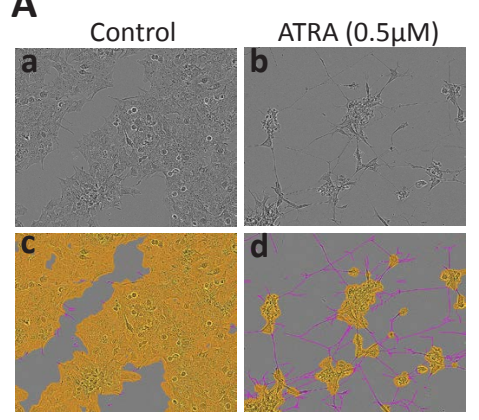

B

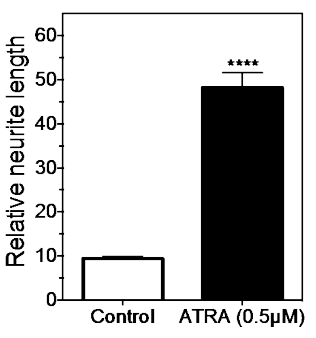

C
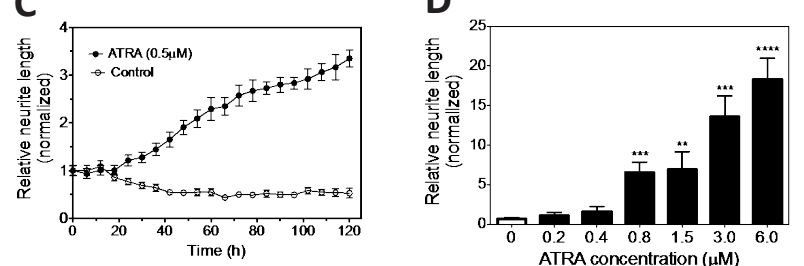

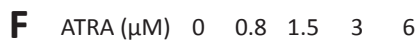
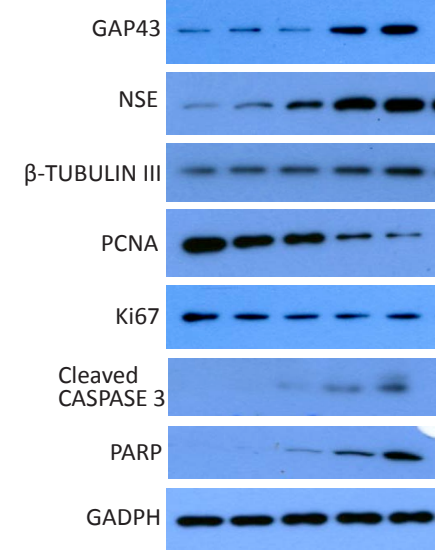

$E$

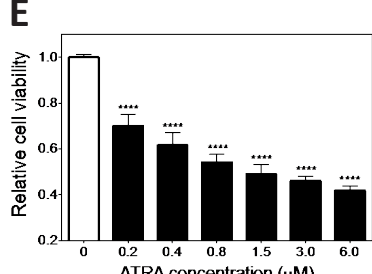

Figure 1: Neurite length is a quantifiable differentiation marker of BE(2)-C cells. 2,500 cells were plated in 96-well plates and cultured overnight. Cells were then treated with ATRA or carrier (DMSO, control) and placed into the IncuCyte for detecting neurite outgrowth. 9 images were taken from each well to allow for statistical analysis. Relative neurite length is defined as neurite length per cell body area. A, ATRA induces neurite outgrowth. Shown are representative phase-contrast images for cells treated with (a) carrier or (b) ATRA for 5 days, and (c, d) the same images analyzed to define neurites (pink) and cell body areas (yellow). B, Quantification shows that ATRA significantly increases the relative neurite length compared to control. C, Relative neurite lengths increase in a time-dependent manner during ATRA-induced cell differentiation. Neurite lengths were normalized to the starting time point $(0 \mathrm{~h})$. D, Dose-dependent effect of ATRA on neurite outgrowth. Shown are the results after treating with ATRA for 5 days. E, Dose-dependent effect of ATRA on cell viability. Cells were treated with different concentrations of ATRA, and cell viability was determined after 5 days. F, Dose-dependent effect of ATRA on the protein expression levels of cell differentiation markers GAP43, NSE and $\beta$-TUBULIN III, cell proliferation markers Ki67 and PCNA, and apoptotic markers cleaved CASPASE 3 and PARP, with GAPDH protein levels used as a loading control. Cells were treated with ATRA as above, and protein levels were determined by Western blots after 5 days. ${ }^{* *}, p<0.01 ;{ }^{* * *}, p<0.001 ;{ }^{* * * *}, p<0.0001$.

A

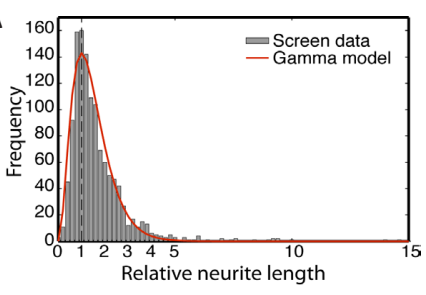

C

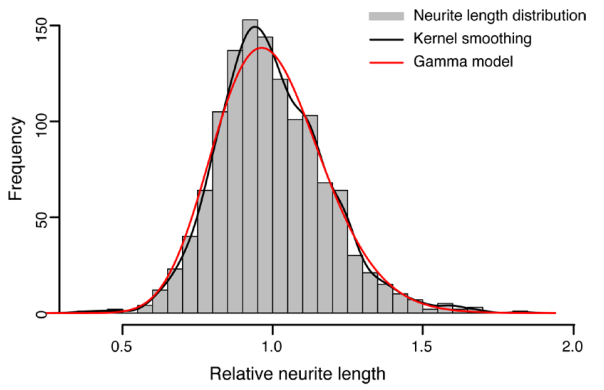

Figure 2: HCS screening of miRNA mimics identifies miRNAs that induce neurite outgrowth in BE(2)-C cells. A-B, 2,500 cells were reverse-transfected with $25 \mathrm{nM}$ miRNA mimics in 96-well plates. After 4 days of transfection, relative neurite lengths were quantified as above. A, The distribution of post-normalized neurite length measurements (grey histogram) for individual miRNA mimics from the screen and the fitted Gamma distribution curve (red line, $\alpha=3.27, \beta=0.444$ ) generated by the method described in Suppl. Figure 3. B, Correlation between two independent neurite length measurements for one library plate. Cells were transfected with $25 \mathrm{nM}$ mimics in two independent 96 -well plates. Normalized neurite lengths were measured as above. Correlation of neurite length between the two plates was analyzed using two-tailed Pearson Correlation with $p<0.05$ considered significant. $\mathrm{C}$, The distribution of the neurite lengths for untreated $\mathrm{BE}(2)-\mathrm{C}$ cells. 2,500 Cells were plated into each well in 96 well plates. After 4 days, neurite lengths were analyzed as above. Shown are the neurite length distribution histogram (grey), the empirical density curve (black line), and the fitted Gamma distribution curve (red line, $\alpha=30.23$, $\beta=0.033$ ). Using the $P<0.05$ threshold, Kolmogorov-Smirnov goodness-of-fit test for Gamma model validity did not reject the null hypothesis $(p=0.16)$, which support that the neurite length distribution fits Gamma model. 
A

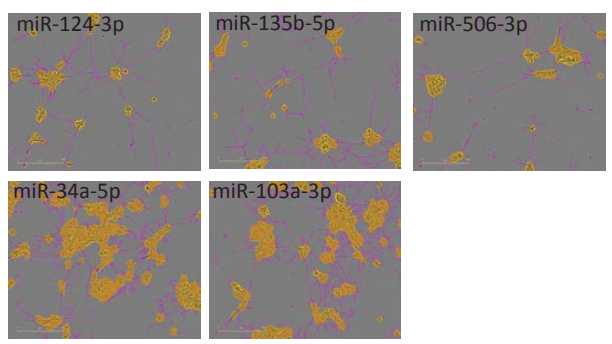

C

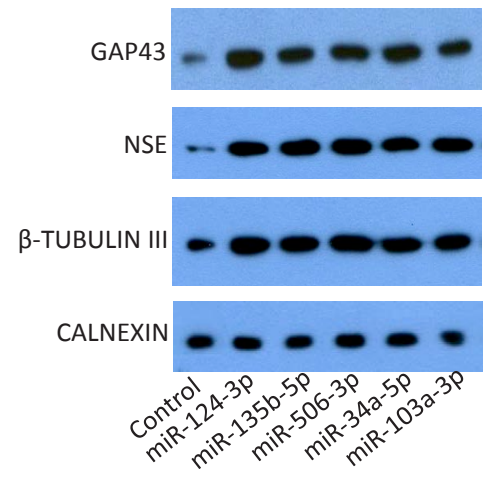

B

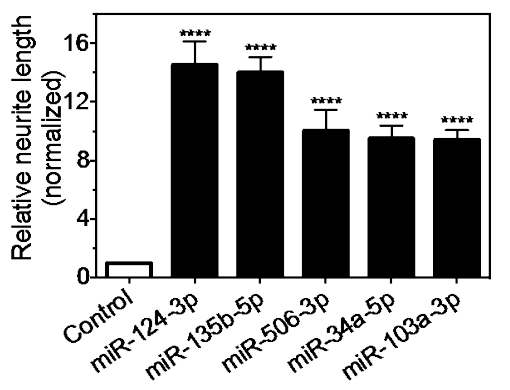

D
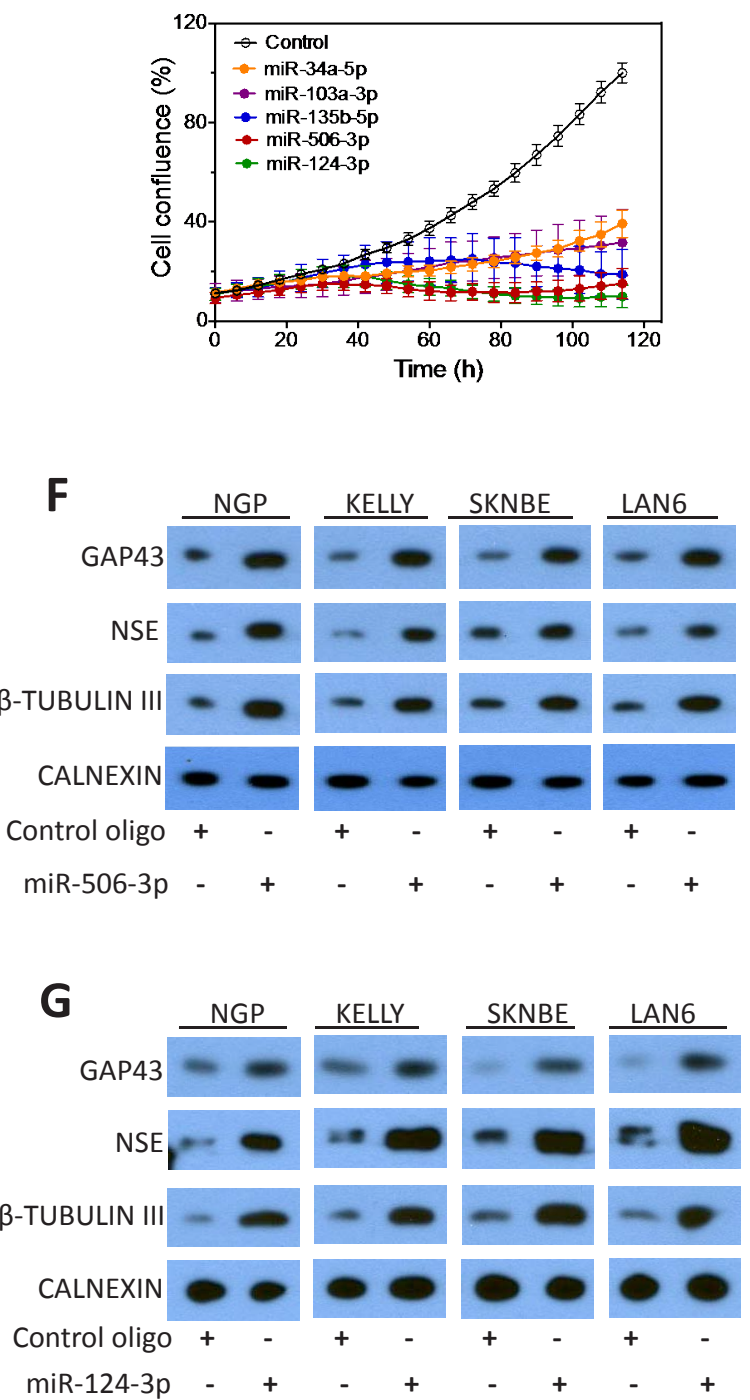

Figure 3: Characterization of the effect of the top 5 neurite-inducing miRNA mimics on cell differentiation and growth in multiple neuroblastoma cell lines. A-B, Effects of the identified top 5 miRNA mimics on neurite outgrowth. BE(2)-C cells were transfected with $25 \mathrm{nM}$ miRNA mimics or control for 4 days, and relative neurite lengths were quantified as above. Shown are representative cell images analyzed to define neurite and cell body areas (A) and neurite length quantifications (B). C, Effects of the 5 miRNA mimics on expression of differentiation markers, with CALNEXIN protein levels used as a loading control. BE(2)-C cells were transfected with $25 \mathrm{nM}$ of the indicated miRNA mimics or control, and proteins levels were examined after 4 days. D, Effects of the 5 miRNA mimics on cell proliferation rate. E, Effect of the 5 miRNAs on neurite outgrowth in multiple cell lines. Cells were transfected with $25 \mathrm{nM}$ miRNA mimics or control, and neurite lengths were quantified as above after 5 days. F-G, Effects of miR-506-3p (F) and miR-124-3p (G) mimics on expression of differentiation markers in multiple cell lines. ${ }^{*}, p<0.05 ; * *, p<0.01 ; * * *, p<0.001 ; * * * *, p<0.0001$. 
Table 1: Fourteen miRNA mimics identified from HCS as inducing neurite outgrowth using a FDR threshold $<0.01$. Shown are the (a) miRNA name, (b) fold change of neurite length relative to unaffected cells, (c) $p$ value, (d) FDR, (e) mature sequences of the miRNAs with seed sequences underlined and seed family grouping indicated in parentheses, and (f) references that have reported the involvements of the corresponding miRNAs in differentiation.

\begin{tabular}{|c|c|c|c|c|c|}
\hline (a) miRNA & $\begin{array}{l}\text { (b) Neurite length } \\
\text { (Mean } \pm \text { SD) }\end{array}$ & (c) p value & (d) FDR & (e) Mature sequence 5'-3' & (f) Ref \\
\hline hsa-miR-124-3p & $14.55 \pm 4.75$ & $1.11 \mathrm{E}-11$ & $1.37 \mathrm{E}-08$ & UAAGGCACGCGGUGAAUGCC (1) & 27,37 \\
\hline hsa-miR-135b-5p & $14.02 \pm 4.29$ & $3.26 \mathrm{E}-11$ & $2.02 \mathrm{E}-08$ & UAUGGCUUUUCAUUCCUAUGUGA & \\
\hline hsa-miR-506-3p & $10.04 \pm 3.41$ & $1.05 \mathrm{E}-07$ & 4.34E-05 & UAAGGCACCCUUCUGAGUAGA (1) & \\
\hline hsa-miR-34a-5p & $9.49 \pm 3.18$ & $3.11 \mathrm{E}-07$ & $8.81 \mathrm{E}-05$ & UGGCAGUGUCUUAGCUGGUUGU (2) & \\
\hline hsa-miR-103a-3p & $9.43 \pm 2.67$ & $3.56 \mathrm{E}-07$ & $8.81 \mathrm{E}-05$ & AGCAGCAUUGUACAGGGCUAUGA (3) & 28 \\
\hline hsa-miR-450b-3p & $9.26 \pm 2.64$ & 4.94E-07 & $1.02 \mathrm{E}-04$ & $\underline{\text { UUGGGAUCAUUUUGCAUCCAUA }}$ & \\
\hline hsa-miR-449a & $9.16 \pm 2.47$ & $6.03 \mathrm{E}-07$ & $1.07 \mathrm{E}-04$ & UGGCAGUGUAUUGUUAGCUGGU (2) & \\
\hline hsa-miR-2110 & $9.00 \pm 2.40$ & $8.21 \mathrm{E}-07$ & $1.27 \mathrm{E}-04$ & UUGGGGAAACGGCCGCUGAGUG & \\
\hline hsa-miR-34b-5p & $8.41 \pm 2.16$ & $2.66 \mathrm{E}-06$ & $3.66 \mathrm{E}-04$ & UAGGCAGUGUCAUUAGCUGAUUG & \\
\hline hsa-miR-107 & $7.60 \pm 1.98$ & $1.27 \mathrm{E}-05$ & $1.55 \mathrm{E}-03$ & AGCAGCAUUGUACAGGGCUAUCA (3) & 36 \\
\hline hsa-miR-3714 & $7.56 \pm 1.91$ & $1.37 \mathrm{E}-05$ & $1.55 \mathrm{E}-03$ & GAAGGCAGCAGUGCUCCCCUGU & \\
\hline hsa-miR-449b-5p & $7.40 \pm 1.85$ & $1.89 \mathrm{E}-05$ & $1.95 \mathrm{E}-03$ & AGGCAGUGUAUUGUUAGCUGGC (2) & \\
\hline hsa-miR-137 & $7.03 \pm 1.36$ & $3.83 \mathrm{E}-05$ & $3.65 \mathrm{E}-03$ & UUAUUGCUUAAGAAUACGCGUAG & 19,34 \\
\hline hsa-miR-3937 & $6.93 \pm 1.05$ & $4.61 \mathrm{E}-05$ & $4.08 \mathrm{E}-03$ & ACAGGCGGCUGUAGCAAUGGGGG & \\
\hline
\end{tabular}

Smirnov goodness-of-fit test for Gamma model validity indicates that the neurite length distribution fit Gamma model $(p=0.16)$, which informs us to use this model (red line in Figure 2A) to assess the effect of individual miRNAs, as illustrated in Suppl. Figure 3. Fourteen miRNA mimics were identified as significantly increasing neurite length using False Discovery Rate (FDR) threshold $<0.01$ (Table 1). Using the same threshold, 0 hits were generated from untreated cells, indicating the specificity of the analysis approach. Among the 14 miRNAs, several were related to neuroblastoma cell differentiation in previous studies (Table 1) [27, 28, 36, 37], demonstrating the sensitivity of our HCS approach.

We next focused on characterizing the differentiation-inducing function of the top 5 microRNAs that are most potent in inducing neurite outgrowth (Figure $3 \mathrm{~A}-\mathrm{B})$. We showed that, comparing to control, the 5 miRNAs induce expression of differentiation markers and dramatically decrease $\mathrm{BE}(2)-\mathrm{C}$ cell growth rate (Figure 3C-D), demonstrating that true cell differentiation and growth arrest are induced. We further investigated the 5 miRNAs in additional neuroblastoma cell lines with different genetic backgrounds (Suppl. Table 1). Among the 5 miRNAs, miR-506-3p and miR-124-3p, which belong to the same seed family (defined as a group of miRNAs that share common seed sequence, Table 1), have the most potent effect on neurite growth (Figure 3E and Suppl. Figure 4). Correspondingly, the two miRNAs dramatically induce expression of differentiation markers in all the tested cell lines (Figure 3F-G). We further show that miR-506-3p and miR-124-3p mimics significantly reduce the ability of $\mathrm{BE}(2)-\mathrm{C}$ to form colonies, indicating their long-term capacity to inhibit cell proliferation (Figure 4A-C). To exclude the possibility that the induced cell differentiation and growth arrest are caused by off-target effects of the specific chemical designs of miRNA mimics, we examined the effect of miR-506-3p and miR-124-3p precursors (Ambion) on differentiation. The miRNA precursors are partially double-stranded RNAs designed to mimic the functions of the endogenous miRNAs, in contrast to the fully complementary double-stranded design of miRNA mimics. Figure 4D-E shows that the precursors significantly induced neurite outgrowth, recapitulating the results with miRNA mimics. This indicates that the differentiation-inducing function of miR-506-3p and miR-124-3p mimics is unlikely caused by off-target effect. Overall, the above results demonstrate the general and potent effect of miR-506-3p/miR-124$3 \mathrm{p}$ on inducing differentiation, suggesting the potential of restoring miR-506-3p and miR-124-3p expressions as a novel differentiation therapeutic strategy to treat neuroblastoma.

To further examine the potential pathophysiological relevance of endogenous miR-506-3p and miR-124-3p in regulating neuroblastoma differentiation, we measured their expression levels in differentiated BE(2)-C cells. Figure $4 \mathrm{~F}$ shows that expressions of both miRNAs are significantly increased in differentiated cells. However, the overexpression of miR-506-3p (380.1 \pm 48.4 fold) is much more dramatic than that of miR-124-3p (8.1 \pm 0.4 fold). These results indicate that endogenous miR-506$3 p$ expression in neuroblastoma cells is highly regulated 
A

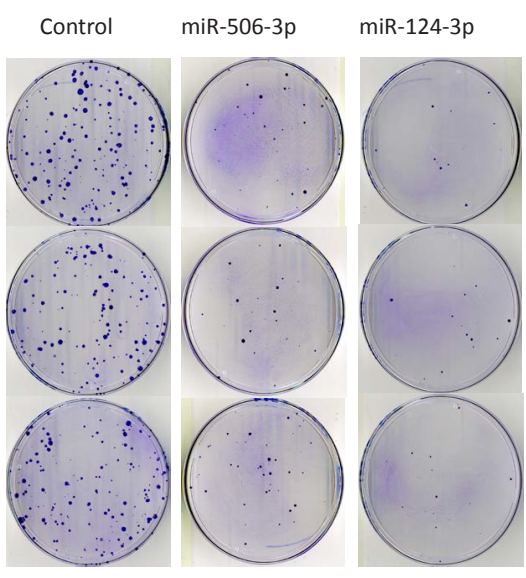

D
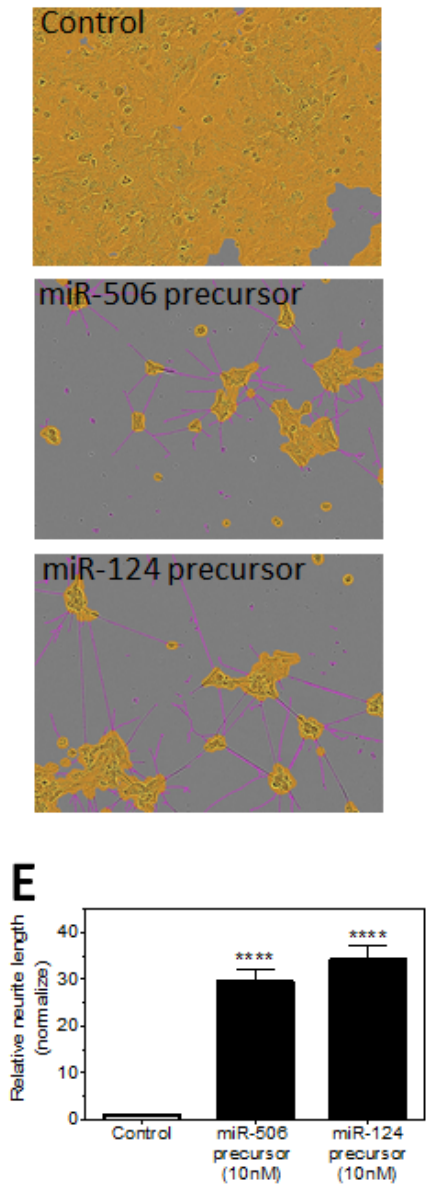

B

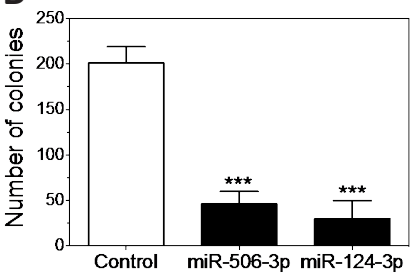

C

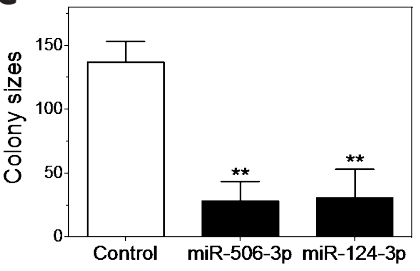

$\mathbf{F}$

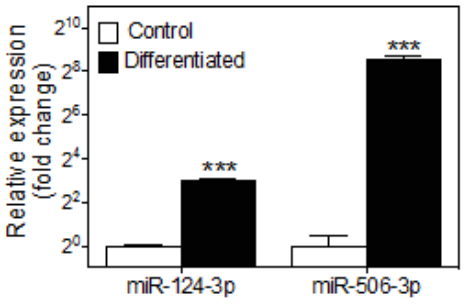

G

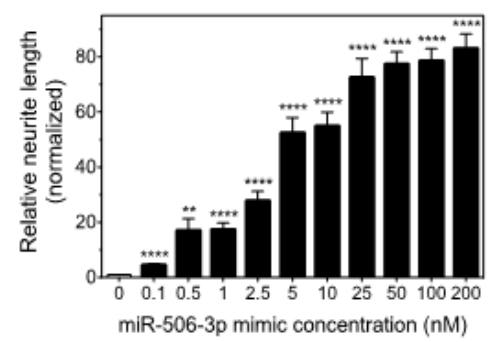

H

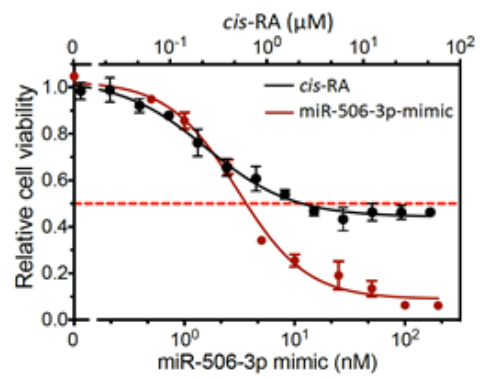

Figure 4: Characterization of the tumor suppressive function of miR-506-3p/miR-124-3p family. A-C, Colony formation assay as a function of miR-124-3p and miR-506-3p mimics. BE(2)-C cells were transfected with the $25 \mathrm{nM}$ of the indicated oligos and colony formation was examined as above. Shown are (A) plate images of colony formation and quantified colony numbers (B) and sizes (C). D-E, Effect of miR-124-3p and miR-506-3p precursors on neurite outgrowth. BE(2)-C cells were transfected with or without $10 \mathrm{nM}$ miRNA precursors. Shown are (D) Representative images analyzed to define neurites and cell body areas after 4 days transfections and (E) quantification of relative neurite lengths. F, Effect of cell differentiation on endogenous expression of miR-506-3p and miR-124-3p in $\mathrm{BE}(2)-\mathrm{C}$ cells. G, Dose-dependent effect of miR-506-3p mimic on neurite outgrowth in BE(2)-C cells. Cells were transfected with different concentrations of miR-506-3p mimic, and relative neurite lengths were quantified as above after 4 days. Neurite lengths were normalized to control $(0 \mathrm{nM})$. H, Dose-dependent effect of miR-506-3p mimic and cis-RA on cell viability in BE(2)-C cells. Cells were transfected with different concentrations of miR-506-3p mimic for 4 days or treated with different concentrations of cis-RA for 5 days, and cell viability was determined as above. *, $p<0.05 ; * *, p<0.01 ; * * *, p<0.001 ; * * * *, p<0.0001$. 
and suggest that, relative to miR-124-3p, endogenous miR-506-3p is likely to be a more dominant driving force in controlling cell differentiation. We further observe that miR-506-3p mimic induces neurite outgrowth and decreases cell viability in a dose-dependent manner, and that the induction of neurite outgrowth is significant at a concentration as low as $0.1 \mathrm{nM}$ (Figure 4G-H, Suppl. Figure 5). Figure $4 \mathrm{H}$ also shows that the cytotoxic effect of miR-506-3p mimic is much more potent (reducing cell viability to $6.3 \pm 0.3 \%$ when reaching plateau) than 13 -cis retinoic acid (cis-RA) (42.6 $\pm 3.7 \%$ ), a differentiationagent currently used to treat neuroblastoma patients [7]. Altogether, these results demonstrate the potent function of miR-506-3p in inducing differentiation and in reducing cell survival and growth. The role of miR-506-3p in neuroblastoma tumorigenesis has not been investigated previously; we are the first to discover its differentiation inducing function in neuroblastoma.

From the screen, we also identified miRNAs that significantly reduce cell survival but do not induce differentiation (Suppl. Figure 6). This indicates that miRNAs modulate neuroblastoma cell survival and growth through distinct mechanisms, and cell differentiation is not a prerequisite for cell death or growth arrest, which supports the functional specificity of the identified differentiation-inducing miRNAs in regulating differentiation.

\section{miRNA seed families that are potent inducers of cell differentiation are discovered from HCS.}

miRNA seed sequences are central in determining their target genes [38-41]. We therefore first analyzed the seed sequences of the identified differentiation-inducing miRNAs. Surprisingly, as shown in Table 1, three miRNA seed families, which accounts for 7 miRNAs, are identified within the 14 miRNAs. Enrichment analysis by random permutation shows that the probability that $\geq 7$ non-unique

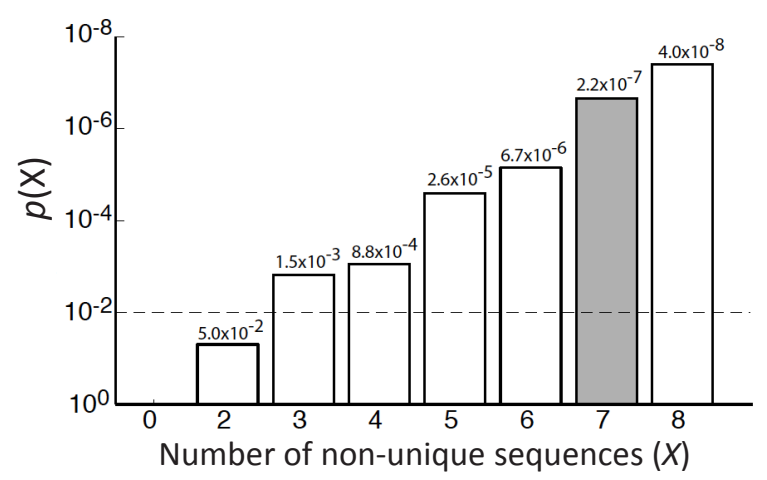

Figure 5: Enrichment analysis of seed families in a set of 14 miRNAs by random permutation. Grey bar shows the probability $\left(p=2.2 \times 10^{-7}\right)$ that at least 7 non-unique seed sequences appear in a randomly selected set of 14 miRNAs. seed sequences appear in a set of 14 randomly drawn miRNAs from the miRNA mimic library is $p=2.2 \times 10^{-7}$ (Grey bar in Figure 5), indicating that miRNA seedsequences families are significantly overrepresented in the identified 14 miRNAs. Further investigation of the remaining 7 miRNAs shows that the seed sequences of miR-135b-5p (shares seed sequence with miR-135a-5p), miR-34b-5p (shares with miR-449c-5p and miR-2682$5 p$ ) and miR-450b-3p (shares with miR-769-3p) are not unique. In addition, seed sequence family 2 includes another miRNA, miR-34c-5p, which is not identified in the top 14 candidates. Close examination of the screen results indicates that miR-34c-5p, miR-135a-5p and miR$449 c-5 p$ also increase the neurite lengths (Suppl. Figure 7 ), ranking as $17^{\text {th }}, 43^{\text {th }}$ and $128^{\text {th }}$ in the screen (miR-2682$5 \mathrm{p}$ was not in the library), although the effect of miR$449 \mathrm{c}-5 \mathrm{p}$ did not reach statistical significance using $p<0.05$ threshold. miR-769-3p does not induce neurite outgrowth, and, however, is the only exception among the identified differentiation-inducing seed families.

\section{The identified differentiation-inducing miRNAs are predicted to target distinct spectra of genes involved in neuroblastoma differentiation.}

The above observations lead us to identify potential miRNA targets based on seed sequence matches. We first identified 48 genes that have been previously demonstrated to regulate neuroblastoma differentiation (Suppl. Table 2.) using Ingenuity Pathway Analysis (IPA) (Ingenuity System). Not surprisingly, further IPA miRNA target analysis indicates that each of the miRNAs/seed families is predicted to target multiple genes involved in neuroblastoma differentiation (Figure 6), among which the $\mathrm{miR}-506-3 \mathrm{p} / \mathrm{miR}-124-3 \mathrm{p}$ family is predicted to target 10 of the 48 genes. The results also show that, although the predicted targets of these miRNAs/seed-sequence families overlap, each miRNA/seed-sequence family has a unique targetome, suggesting that they are likely to induce cell differentiation through distinct, but overlapping pathways.

\section{CDK4 and STAT3 play a role in mediating the differentiation-inducing function of miR-506-3p/ miR-124-3p family.}

We further investigated the targets of miR-506-3p/ miR-124-3p family. Table 2 shows that the expression changes of the 10 predicted target genes of miR-506-3p/ miR-124-3p induced by their overexpressions are almost identical (Table 2), further demonstrating that the seedsequence is dominant in determining the miRNA function. The two miRNAs dramatically down-regulate two of the ten predicted targets, CDK4 and STAT3. Figure 7A shows the interactions of the two miRNAs with the predicted target sites in the 3'UTR of CDK4 and STAT3. We 
validated their target sites in the 3'UTRs of CDK4 and STAT3 using luciferase reporter assays (Figure 7B-C). We further show that overexpressions of the two miRNAs down-regulate endogenous CDK4 and STAT3 protein levels (Figure 7D). Figure 7E-F shows that individual repression of $C D K 4$ and $S T A T 3$ expression induces neurite outgrowth, and that their combined repression has an enhanced effect on neurite outgrowth relative to individual repression. These results indicate that CDK4 and STAT3 mediate, at least partially, the differentiation-inducing function of miR-506-3p/miR-124-3p, and suggest that the effect of miR-506-3p/miR-124-3p on cell differentiation are most likely mediated by concordantly down-regulating multiple target genes.

\section{DISCUSSION}

In this study, we developed a HCS approach to facilitate the discovery of novel differentiation-inducing agents for neuroblastoma. Several HCS approaches based on quantification of neurite outgrowth have been described [33, 42-44]. However, quantifications of neurite outgrowth in these approaches were either based on cell lines engineered to express fluorescent reporters or involve
Table 2: Changes of expression for the 10 predicted targets of the miR-506-3p/miR-124-3p family induced by miR-506-3p and miR-124-3p overexpression. Shown are the gene name and the fold change of mRNA expression levels (miRNA mimic vs. control) induced after 24 $\mathrm{h}$ transfection with (1) miR-506-3p mimic and (2) miR-124-3p mimic. *, Shown are average expressions detected by multiple probes in the microarray.

\begin{tabular}{|l|l|l|}
\hline \multirow{2}{*}{ Gene } & \multicolumn{2}{|c|}{ Gene expression* } \\
\cline { 2 - 3 } & $(1) \mathrm{miR}-506-3 \mathrm{p}$ & $(2) \mathrm{miR}-124-3 \mathrm{p}$ \\
\hline CDK4 & 0.39 & 0.43 \\
\hline STAT3 & 0.75 & 0.75 \\
\hline CEBPA & 0.88 & 0.86 \\
\hline PML & 1.01 & 1.00 \\
\hline RARG & 1.02 & 1.03 \\
\hline BDNF & 1.04 & 1.06 \\
\hline THRB & 1.04 & 1.06 \\
\hline RHOQ & 1.07 & 1.13 \\
\hline SHC3 & 1.08 & 1.07 \\
\hline AHR & 1.19 & 1.17 \\
\hline
\end{tabular}

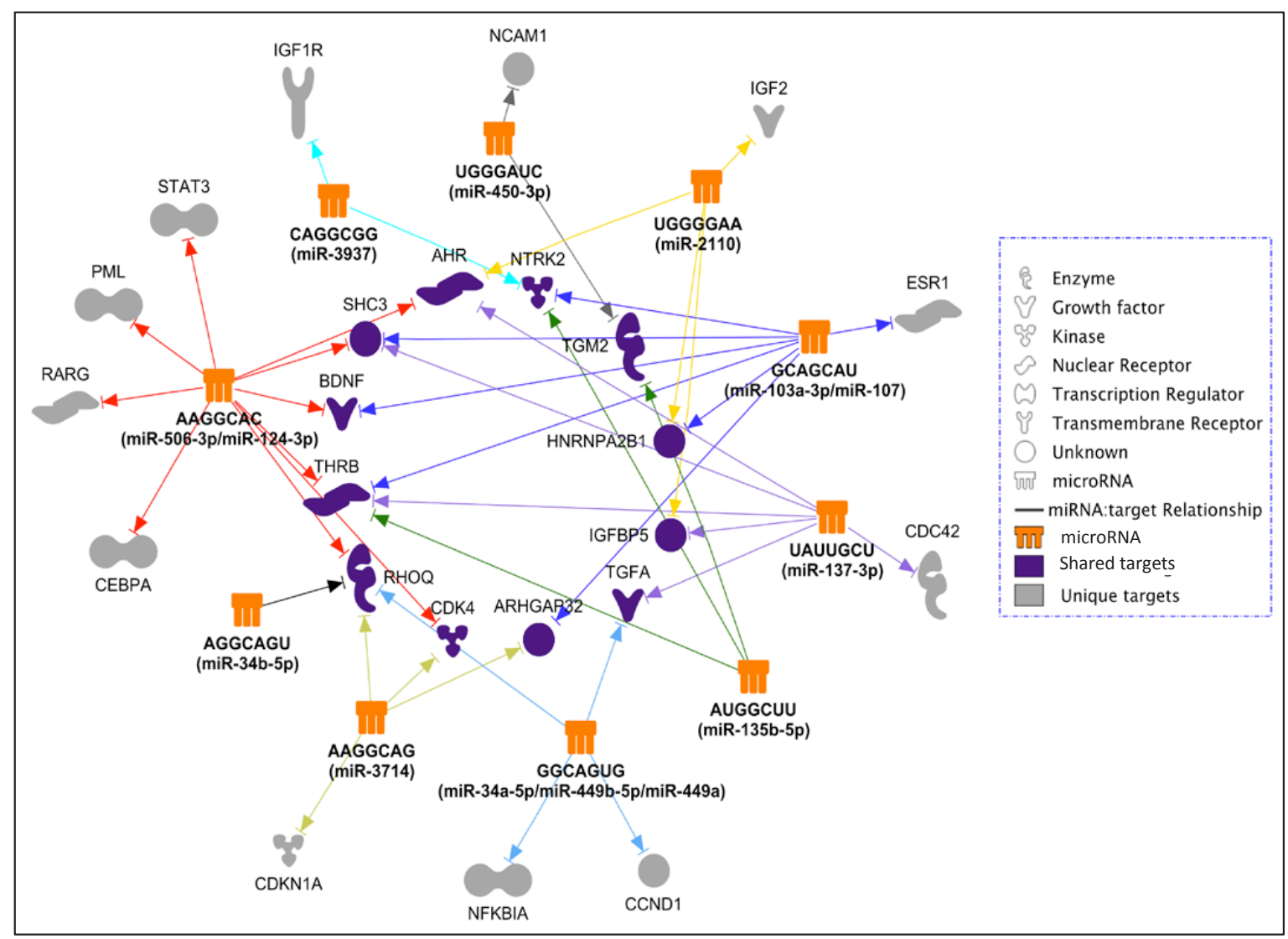

Figure 6: The predicted differentiation-inducing targetome network for the identified 14 differentiation-inducing miRNAs. The 14 miRNAs were grouped into 10 seed-sequence groups. Predicted targets previously reported as involved in neuroblastoma differentiation were used to create the targetome network. 
staining of fixed cells [33, 42-44]. These approaches are generally time-consuming. In addition, whether the extent of neurite outgrowth in neuroblastoma cells is a reliable marker to evaluate the potency of differentiation-inducing agents was not clearly characterized. Here we showed that, in neuroblastoma cell line $\mathrm{BE}(2)-\mathrm{C}$, neurite length of differentiated cells is quantifiable based on phase-contrast images of live cells and is a reliable marker of the extent of cell differentiation. This supports us to develop a HCS approach to examine neuroblastoma cell differentiation by quantifying neurite outgrowth, and we for the first time show that the neurite length distribution of untreated cells fit the Gamma model - this informs us to use this model to perform statistical analysis on neurite-based HCS. Our screen of a library of miRNA mimics demonstrates that our screening and statistical analysis methods are specific and sensitive for identifying differentiation-inducing agents. We expect that this approach will facilitate future discovery of novel differentiation-inducing drugs and drug targets for treating neurobloastoma.

Our study provides the first comprehensive and direct functional analysis of miRNA species in inducing neuroblastoma cell differentiation. Our screen not only recapitulated several previous findings, but also identified miRNAs that have not been known to regulate neuroblastoma differentiation. For example, we are the first to identify the function of miR-506-3p in promoting neuroblastoma cell differentiation. Our further investigations show that endogenous miR-506-3p expression was dramatically increased in differentiated neuroblastoma cells. In addition, published data have indicated the tissue-specific expression of miR506 in adrenal gland, the primary tissue of origin for neuroblastoma [45]. This evidence altogether implicated the important role of miR-506-3p in neuroblastoma pathogenesis. Overall, our comprehensive analysis of miRNAs in neuroblastoma cell differentiation is the first step towards elucidating the entire picture of miRNA
A
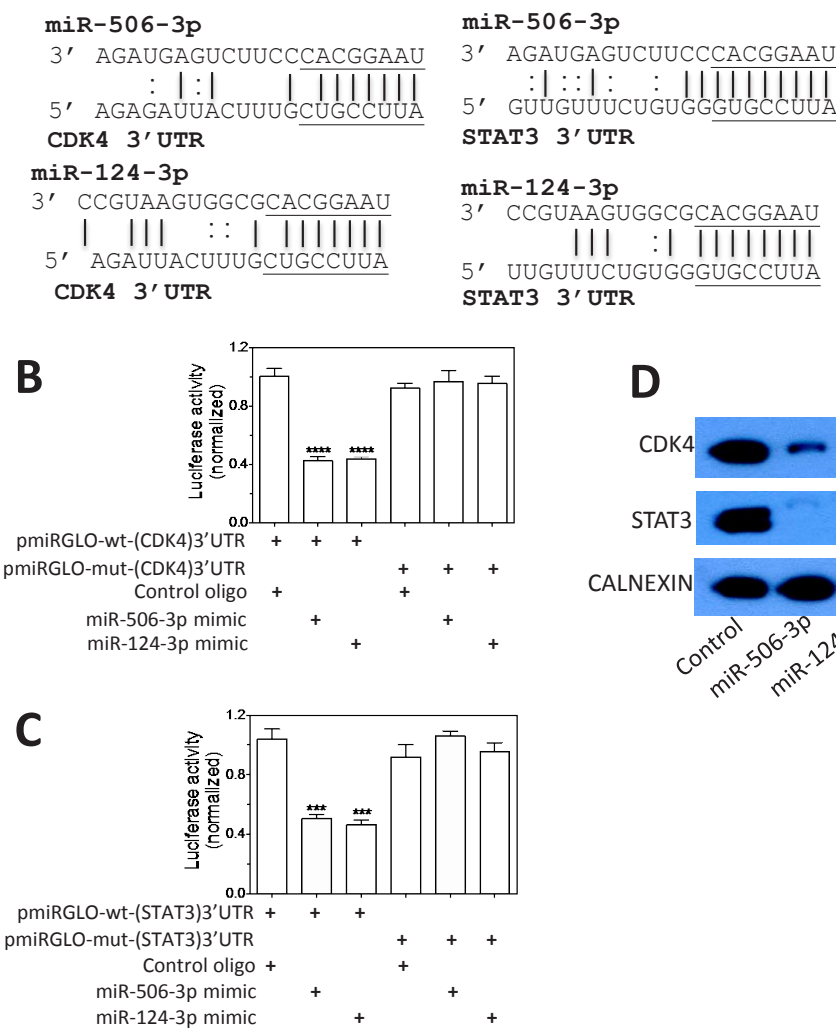
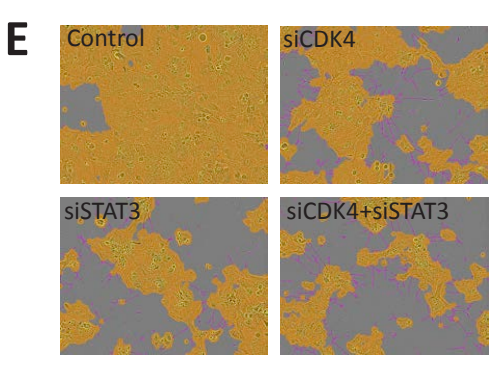

$\mathbf{F}$

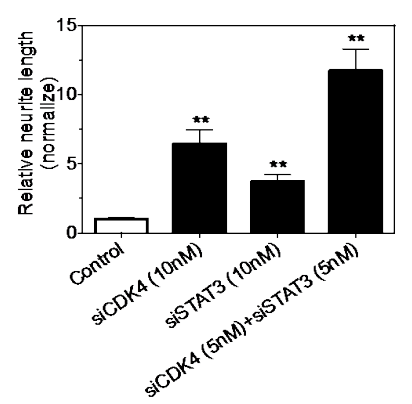

Figure 7: Validation of CDK4 and STAT3 as direct targets that mediate the differentiation-inducing function of miR506-3p and miR-124-3p. A, The predicted interactions between miR-506-3p/miR-124-3p and the target sites in the 3'UTR of STAT3 and CDK4 mRNAs. The seed sequences are underlined. B-C, Validation of the target sites of miR-506-3p and miR-124-3p in the 3'UTRs of (B) CDK4 and (C) STAT3 by luciferase reporter assay. BE(2)-C cells were co-transfected with the indicated vectors and miRNA mimics or control oligo. After $72 \mathrm{~h}$ of transfection, cells were lysed and luciferase activity was measured. Shown are normalized luciferase activities of different treatment groups. D, miR-506-3p and miR-124-3p overexpression down-regulate endogenous CDK4 and STAT3 protein expression levels. Cells were transfected as above for 4 days, and protein levels were measured by Western blots. E-F, Effect of CDK4 and STAT3 knockdown on neurite outgrowth in BE(2)-C cells. Cells were transfected with the indicated oligos, and neurite lengths were measured as above after 4 days transfection. Shown are representative cell images analyzed to define neurites and cell body areas $(\mathrm{G})$ and quantification of neurite length under the indicated treatment conditions $(\mathrm{H}) .{ }^{* *}, p<0.01 ; * * *, p<0.001 ; * * * *, p<0.0001$. 
involvement in differentiation. We expect that further investigation on the identified individual miRNAs will provide a better understanding of the mechanisms of neuroblastoma tumorigenesis.

In our HCS, several miRNAs that were previously reported to induce neuroblastoma cell differentiation were not identified as potent inducers of cell differentiation [29, 30]. One of the possible explanations is the cell contextspecific variation of the function of these miRNAs, in that our screen was conducted in a different cell line from those used in previous studies. Further studies are certainly warranted to compare the differentiation-inducing function of these previously reported miRNAs with the miRNAs identified in our study in a larger panel of neuroblastoma cell lines and in in vivo studies, and to compare their clinical relevance in neuroblastoma tumorigenesis in clinical studies.

Another intriguing finding in our study is the overrepresentation of a set of miRNA seed families in our identified differentiation-inducing miRNAs. This observation is beyond providing convincing evidence supporting the reliability of our HCS approach. It leads us to an interesting speculation: the conservation of seed sequence among different miRNAs located at different genomic regions may be an important evolution trait that is selected by nature to guard the normal cell differentiation process during development; if one miRNA fails its expression in cells, expression of another seedfamily member will perform similar function to prevent differentiation error. If this is true, we expect that miRNA seed sequence families are more likely to be involved in cell differentiation than miRNAs with unique sequences. There are certainly other possible explanations. Whether miRNA seed families are also overrepresented in other differentiation/development processes and what are the pathophysiological significances of this overrepresentation are certainly interesting questions to pursue in the future.

Previous studies have demonstrated the promise of synthetic miRNA mimics as therapeutic agents in cancer treatment $[20,22]$. Our identification of novel differentiation-inducing miRNA mimics therefore directly provides a group of novel candidates potentially applicable to treat neuroblastoma. Our identification of several seedsequence families that are potent differentiation inducers reinforces the notion that miRNA seed sequences play the key role in defining their biological function, which provides the rationale for developing novel synthetic seed sequence-based oligos as differentiation-inducing agents. By replacing the nucleic acids in the non-seed positions while keeping the seed sequence unchanged, various seed sequence-based synthetic oligos can be designed and tested in vitro and in vivo, in order to identify the optimal design that has the most potent effect on neuroblastoma differentiation and has minimal non-specific cytotoxicity on normal cells and tissues.

Currently, differentiation agents are limited to be used for post-remission maintenance therapy in high-risk neuroblastoma [2]. One of the reasons for this limitation is that the current available differentiation agents are not as potent as other anti-cancer agents in ablating cancer cells. However, our study show that miR-506-3p mimic reduced neuroblastoma cell viability to a much greater extent than cis-RA, raising the possibility of applying differentiationinducing miRNA mimics to remission induction therapy. Further investigations in in vivo models are certainly warranted to examine the therapeutic efficacy of miR-506$3 \mathrm{p}$ mimics.

In this study, we preliminarily analyzed the predicted targetomes of the identified top 14 differentiation-inducing miRNAs using informatics tools, and took a small step toward validating the predicted targets of miR-506-3p/ miR-124-3p family. Our investigation suggests that the differentiation-inducing function of a miRNA is likely mediated by concordantly down-regulating multiple targets. Our current analysis is limited to genes that are known to regulate neuroblastoma differentiation. It is highly likely that there are undiscovered targets of these miRNAs that play important roles in mediating their differentiation-inducing functions. Indeed, our expression array analyses indicate that miR-506-3p/miR-124-3p overexpression down-regulates many more of their predicted targets than we investigated in this study (data not shown). Whether these targets play roles in mediating their differentiation-inducing function warrants further investigation.

In summary, we have established a HCS platform to screen for novel differentiation-inducing substances in neuroblastoma cells. We have identified novel miRNAs and miRNA seed families that induce neuroblastoma cell differentiation. Our study not only provides the first comprehensive understanding of the role of miRNAs in neuroblastoma differentiation, but also provides novel leads for developing miRNA-based differentiation agents for neuroblastoma treatment. We expect that further investigation based on our findings will not only promote better understanding of the mechanisms of neuroblastoma tumorigenesis, but may also provide new therapeutic strategies for treating neuroblastoma.

\section{MATERIALS AND METHODS}

\section{Materials}

ATRA and cis-RA were from Sigma (St Luis, MO, USA). Dharmacon miRNA mimic library and individual miRNA mimics were from Thermo Fisher Scientific (Rockford, IL, USA). miRNA precursors were purchased from Ambion (Foster City, CA, USA). Rabbit anti-GAP43, anti-NSE, and anti- $\beta$-TUBULIN III were from Abcam (Cambridge, MA, USA). Rabbit anti-CALNEXIN, 
anti-GAPDH and goat anti-rabbit secondary antibody conjugated with horseradish peroxidase (HRP) were from Santa Cruz (Dallas, TX, USA). Rabbit anti-PARP (cleaved), anti-CASPASE-3, anti-STAT3, and anti-CDK4, were from Cell Signaling (Danvers, MA, USA). Rabbit anti-Ki67 was from Millipore (Billerica, MA, USA).

\section{Cell lines.}

BE(2)-C cells were purchased from the ATCC. Other cell lines were obtained from the cell line repository at the Greehey Children's Cancer Research Institute. Cells were grown in DMEM/F12 supplemented with $10 \%$ fetal bovine serum.

\section{Detection and quantification of neurite outgrowth.}

Cells were plated and treated in 96-well plates. For detecting neurite outgrowth, cells were placed into ZOOM IncuCyte Imaging System (Essen BioScience) and cell images were taken under 20X microscopic magnification. For detecting neurite outgrowth in a time-dependent manner, cell images were taken every $6 \mathrm{~h}$. The neurite lengths associated with each treatment were calculated using the neurite definition defined for each specific cell line using the NeuroTrack system (Essen BioScience).

\section{Analysis of HCS data.}

The relative neurite length associated with cells in each well on the screen plates was determined as above. In order to allow for plate-to-plate comparison, neurite length associated with each well in each plate was first internally normalized to the mean of the corresponding plate, and multiple screen plates were then aggregated together to generate the neurite length distribution. The data was then further analyzed to determine the distribution of the unaffected cells as described below, and to identify differentiation-inducing miRNA mimics as illustrated in Suppl. Figure 3.

\section{Kolmogorov-Smirnov goodness-of-fit test for Gamma model validity.}

In order to examine whether the neurite length distribution of the untreated cells fit Gamma distribution, Gaussian kernel smoothing was first performed to generate the empirical density curve based on the neurite length distribution histogram of the untreated cells, and Gamma model parameters $(\alpha, \beta)$ were then estimated by minimizing the area in between empirical and Gamma distribution curves. Statistical significance of the fitness to Gamma distribution was examined by KolmogorovSmirnov goodness-of-fit test, with $p<0.05$ considered as rejecting the null hypothesis that the neurite length distribution fits Gamma distribution.

\section{Western blots.}

Cell lysates were prepared using RIPA buffer. Protein concentration was determined using the Pierce BCA assay (Thermo Fisher Scientific). For electrophoresis, equal amounts of cell lysate were resolved by SDS-PAGE and transferred to Immun-Blot PVDF membranes (Bio-Rad Laboratories). Membranes were blocked and probed with primary antibodies to specific proteins. Bound antibodies were detected with secondary antibodies conjugated with horseradish peroxidase (HRP) visualized by enhanced chemiluminescent (ECL) substrate (Pierce).

\section{Cell growth rate assay.}

Cells were plated in 96-well plates and were treated with specified conditions. Cells were placed into the IncuCyte imaging system and cell confluence was monitored every $6 \mathrm{~h}$ for $120 \mathrm{~h}$. Cell growth curves were derived by comparing the cell confluences at different time points.

\section{Cell viability assay.}

Cells were plated in 96-well format and treated as specified. After culturing for $120 \mathrm{~h}$, cell viability was determined using the CellTiter-Glo Luminescent Cell Viability Assay (Promega).

\section{Colony formation assay.}

Cells were transfected as specified and cultured overnight. 500 cells were re-plated in $10 \mathrm{~cm}$ dishes. After 14 days, colonies were visualized by staining with $1 \%$ crystal violet. Colony numbers and sizes were analyzed using Image $\mathrm{J}$ (NIH, Bethesda, MD).

\section{Enrichment analysis of miRNA seed families.}

We use random permutation to examine whether miRNA seed families are significantly enriched in the identified set of differentiation-inducing miRNAs. The miRNA mimic library includes mimics for 1231 human miRNAs listed in miRBase 16.0. Among these miRNAs, 900 miRNAs have unique seed sequences; 331 miRNAs share seed sequences with at least one other miRNA, constituting 125 seed sequence families. To calculate the probability of miRNAs from the same seed families randomly appears in a set of 14 miRNAs, 14 miRNAs 
were randomly drawn from the 1231 miRNAs, and the number of non-unique seed sequences within the 14 miRNAs is counted $(\mathrm{X}) .10^{8}$ permutations were run to determine the probability that at least $\mathrm{X}$ non-unique seed sequences appear in a randomly selected set of 14 $\operatorname{miRNAs}(p(X))$.

\section{miRNA target prediction and pathway analysis.}

miRNA target sites in 3'UTRs were predicted based on seed sequence complementarity and were identified using the IPA Pathway analysis function, which identifies any 7-nucleotide region (3'-5') in a given 3'UTR completely complementary to the seed sequence of a miRNA $\left(2^{\text {nd }}-8^{\text {th }}\right.$ or $1^{\text {st }}-7^{\text {th }}$ nucleotides, $\left.5^{\prime}-3^{\prime}\right)$ as a potential target site of this miRNA. To identify targets that potentially mediate the differentiation-inducing function of our identified miRNAs, we first identified the genes that have been known to relate to neuroblastoma differentiation using IPA. From this gene list, we identified the predicted targets for each miRNA and generated the predicted miRNA:target interaction network mediating the differentiation-inducing function of the identified miRNAs.

\section{mRNA and miRNA expression.}

Total RNA was isolated as previously described [46]. mRNA expression profiling was done using the Illumina mRNA WG-6 v3 microarray platform. miRNA expression was measured by qRT-PCR using TaqMan microRNA Assays (Life Technologies) with average expression of RNU44 RNA, RNU19 RNA, GAPDH mRNA and 18s rRNA used as controls for normalizing RNA loading.

\section{Luciferase reporter assay.}

The segments of the wildtype 3'UTRs for CDK4 and STAT3 containing the predicted target sites of miR-506-3p and miR-124-3p were cloned from human genomic DNA. Mutant constructs were generated with the seed target site (GUGCCUU) replaced by CACGGUU. The 3'UTRs were cloned downstream of the firefly luciferase coding sequences into the pmirGLO dual-luciferase reporter (Promega), a vector containing both firefly and Renilla luciferase cDNAs under the control of separate promoter/ terminator systems. The firefly luciferase was used as the primary reporter for miRNA regulation of the 3'UTR. The Renilla luciferase is an internal control for normalization. $\mathrm{BE}(2)-\mathrm{C}$ cells were co-transfected with luciferase reporters $(0.8 \mathrm{ng} / \mathrm{ul})$ and miRNA mimics or control oligonucleotide (oligo) (25 nM). Luciferase activities were measured after 72 h using the Dual-Glo Luciferase Assay System
(Promega). Firefly luciferase activity was normalized to Renilla luciferase activity to evaluate the effect of the miRNAs.

\section{Statistical analysis.}

For HCS, $p$-value for neurite length associated with each miRNA mimic was evaluated by assuming the distribution of neurite lengths follows a Gamma distribution, and FDR was determined by BenjaminiHochberg correction method for multiple tests [47]. We consider a miRNA with FDR $<0.01$ as significantly inducing neurite outgrowth. For all other conditions, the statistical significance for each treatment was determined using $t$-test by comparing the treatment group with control, with $p<0.05$ considered statistically significant.

\section{ACKNOWLEDGEMENT}

The authors thank Dr. Luzhe Sun for critical reading of the manuscript.

\section{GRANT SUPPORT}

This work was supported in part by PRMRP Discovery Award PR121532 from the Department of Defense (to L. Du), NIH Cancer Center Support Grants P30 CA054174-17 (to L. Du, Y. Chen, A. Pertsemlidis, G.E. Tomlinson), NIH CTSA 1UL1RR025767-01 (to Y. Chen), and Greehey Children's Cancer Research Institute microRNA and Pediatric Cancer Pilot Award (to L. Du).

\section{REFERENCES}

1. Maris JM, Hogarty MD, Bagatell R, Cohn SL. Neuroblastoma. Lancet 2007;369(9579):2106-2120.

2. Park JR, Eggert A, Caron H. Neuroblastoma: biology, prognosis, and treatment. Hematol Oncol Clin North Am 2010;24(1):65-86.

3. Brodeur GM. Neuroblastoma: biological insights into a clinical enigma. Nat Rev Cancer 2003;3(3):203-216.

4. Reynolds CP. Differentiating agents in pediatric malignancies: retinoids in neuroblastoma. Curr Oncol Rep 2000;2(6):511-518.

5. Cruz FD, Matushansky I. Solid tumor differentiation therapy - is it possible? Oncotarget 2012;3(5):559-567.

6. Nowak D, Stewart D, Koeffler HP. Differentiation therapy of leukemia: 3 decades of development. Blood 2009;113(16):3655-3665.

7. Matthay KK, Reynolds CP, Seeger RC, Shimada H, Adkins ES, Haas-Kogan D, Gerbing RB, London WB, Villablanca JG. Long-term results for children with high-risk neuroblastoma treated on a randomized trial of myeloablative therapy followed by 13-cis-retinoic 
acid: a children's oncology group study. J Clin Oncol 2009;27(7):1007-1013.

8. Matthay KK, Villablanca JG, Seeger RC, Stram DO, Harris RE, Ramsay NK, Swift P, Shimada H, Black CT, Brodeur GM, Gerbing RB, Reynolds CP. Treatment of high-risk neuroblastoma with intensive chemotherapy, radiotherapy, autologous bone marrow transplantation, and 13-cisretinoic acid. Children's Cancer Group. N Engl J Med 1999;341(16):1165-1173.

9. Conrad C, Gerlich DW. Automated microscopy for highcontent RNAi screening. J Cell Biol 2010;188(4):453-461.

10. Jan E, Byrne SJ, Cuddihy M, Davies AM, Volkov Y, Gun'ko YK, Kotov NA. High-content screening as a universal tool for fingerprinting of cytotoxicity of nanoparticles. ACS Nano 2008;2(5):928-938.

11. Thiele CJ, Reynolds CP, Israel MA. Decreased expression of $\mathrm{N}$-myc precedes retinoic acid-induced morphological differentiation of human neuroblastoma. Nature 1985;313(6001):404-406.

12. Pahlman S, Odelstad L, Larsson E, Grotte G, Nilsson K. Phenotypic changes of human neuroblastoma cells in culture induced by 12-O-tetradecanoyl-phorbol-13-acetate. Int J Cancer 1981;28(5):583-589.

13. Reynolds CP, Perez-Polo JR. Induction of neurite outgrowth in the IMR-32 human neuroblastoma cell line by nerve growth factor. J Neurosci Res 1981;6(3):319-325.

14. Prasad KN, Kumar S. Role of cyclic AMP in differentiation of human neuroblastoma cells in culture. Cancer 1975;36(4):1338-1343.

15. Shenouda SK, Alahari SK. MicroRNA function in cancer: oncogene or a tumor suppressor? Cancer Metastasis Rev 2009;28(3-4):369-378.

16. Li M, Li J, Ding X, He M, Cheng SY. microRNA and cancer. Aaps J 2010;12(3):309-317.

17. Kinoshita T, Hanazawa T, Nohata N, Kikkawa N, Enokida H, Yoshino H, Yamasaki T, Hidaka H, Nakagawa M, Okamoto Y, Seki N. Tumor suppressive microRNA-218 inhibits cancer cell migration and invasion through targeting laminin-332 in head and neck squamous cell carcinoma. Oncotarget 2012;3(11):1386-1400.

18. Kopp F WE, Roidl A. The proto-oncogene KRAS is targeted by miR-200c. Oncotarget 2013.

19. Bier A, Giladi N, Kronfeld N, Lee HK, Cazacu S, Finniss S, Xiang C, Poisson L, de Carvalho AC, Slavin S, Jacoby E, Yalon M, Toren A, et al. MicroRNA-137 is downregulated in glioblastoma and inhibits the stemness of glioma stem cells by targeting RTVP-1. Oncotarget 2013;4(5):665-676.

20. Kota J, Chivukula RR, O'Donnell KA, Wentzel EA, Montgomery CL, Hwang HW, Chang TC, Vivekanandan P, Torbenson M, Clark KR, Mendell JR, Mendell JT. Therapeutic microRNA delivery suppresses tumorigenesis in a murine liver cancer model. Cell 2009;137(6):10051017.

21. Krutzfeldt J, Rajewsky N, Braich R, Rajeev KG, Tuschl T,
Manoharan M, Stoffel M. Silencing of microRNAs in vivo with 'antagomirs'. Nature 2005;438(7068):685-689.

22. Trang P, Wiggins JF, Daige CL, Cho C, Omotola M, Brown D, Weidhaas JB, Bader AG, Slack FJ. Systemic delivery of tumor suppressor microRNA mimics using a neutral lipid emulsion inhibits lung tumors in mice. Mol Ther 2011;19(6):1116-1122.

23. Lin RJ, Lin YC, Chen J, Kuo HH, Chen YY, Diccianni $\mathrm{MB}$, London WB, Chang CH, Yu AL. microRNA signature and expression of Dicer and Drosha can predict prognosis and delineate risk groups in neuroblastoma. Cancer Res 2010;70(20):7841-7850.

24. Chang TC, Yu D, Lee YS, Wentzel EA, Arking DE, West KM, Dang CV, Thomas-Tikhonenko A, Mendell JT. Widespread microRNA repression by Myc contributes to tumorigenesis. Nat Genet 2008;40(1):43-50.

25. Wei JS, Song YK, Durinck S, Chen QR, Cheuk AT, Tsang P, Zhang Q, Thiele CJ, Slack A, Shohet J, Khan J. The MYCN oncogene is a direct target of miR-34a. Oncogene 2008;27(39):5204-5213.

26. Tivnan A, Tracey L, Buckley PG, Alcock LC, Davidoff AM, Stallings RL. MicroRNA-34a is a potent tumor suppressor molecule in vivo in neuroblastoma. BMC Cancer 2011;11:33.

27. Makeyev EV, Zhang J, Carrasco MA, Maniatis T. The MicroRNA miR-124 promotes neuronal differentiation by triggering brain-specific alternative pre-mRNA splicing. Mol Cell 2007;27(3):435-448.

28. Annibali D, Gioia U, Savino M, Laneve P, Caffarelli E, Nasi S. A new module in neural differentiation control: two microRNAs upregulated by retinoic acid, miR-9 and -103 , target the differentiation inhibitor ID2. PLoS One 2012;7(7):e40269.

29. Le MT, Xie H, Zhou B, Chia PH, Rizk P, Um M, Udolph G, Yang H, Lim B, Lodish HF. MicroRNA-125b promotes neuronal differentiation in human cells by repressing multiple targets. Mol Cell Biol 2009;29(19):5290-5305.

30. Foley NH, Bray I, Watters KM, Das S, Bryan K, Bernas T, Prehn JH, Stallings RL. MicroRNAs 10a and 10b are potent inducers of neuroblastoma cell differentiation through targeting of nuclear receptor corepressor 2. Cell Death Differ 2011;18(7):1089-1098.

31. Swarbrick A, Woods SL, Shaw A, Balakrishnan A, Phua Y, Nguyen A, Chanthery Y, Lim L, Ashton LJ, Judson RL, Huskey N, Blelloch R, Haber M, et al. miR-380-5p represses p53 to control cellular survival and is associated with poor outcome in MYCN-amplified neuroblastoma. Nat Med 2010;16(10):1134-1140.

32. Mishra PJ, Merlino G. MicroRNA reexpression as differentiation therapy in cancer. $\mathrm{J}$ Clin Invest 2009;119(8):2119-2123.

33. Radio NM, Breier JM, Shafer TJ, Mundy WR. Assessment of chemical effects on neurite outgrowth in PC12 cells using high content screening. Toxicol Sci 2008;105(1):106- 
118.

34. Cheung YT, Lau WK, Yu MS, Lai CS, Yeung SC, So KF, Chang RC. Effects of all-trans-retinoic acid on human SHSY5Y neuroblastoma as in vitro model in neurotoxicity research. Neurotoxicology 2009;30(1):127-135.

35. Mao L, Ding J, Zha Y, Yang L, McCarthy BA, King W, Cui H, Ding HF. HOXC9 links cell-cycle exit and neuronal differentiation and is a prognostic marker in neuroblastoma. Cancer Res 2011;71(12):4314-4324.

36. Smith B, Treadwell J, Zhang D, Ly D, McKinnell I, Walker PR, Sikorska M. Large-scale expression analysis reveals distinct microRNA profiles at different stages of human neurodevelopment. PLoS One 2010;5(6):e11109.

37. Silber J, Lim DA, Petritsch C, Persson AI, Maunakea AK, Yu M, Vandenberg SR, Ginzinger DG, James CD, Costello JF, Bergers G, Weiss WA, Alvarez-Buylla A, et al. miR124 and miR-137 inhibit proliferation of glioblastoma multiforme cells and induce differentiation of brain tumor stem cells. BMC Med 2008;6:14.

38. Krek A, Grun D, Poy MN, Wolf R, Rosenberg L, Epstein EJ, MacMenamin P, da Piedade I, Gunsalus KC, Stoffel M, Rajewsky N. Combinatorial microRNA target predictions. Nat Genet 2005;37(5):495-500.

39. Lewis BP, Burge CB, Bartel DP. Conserved seed pairing, often flanked by adenosines, indicates that thousands of human genes are microRNA targets. Cell 2005;120(1):1520.

40. Stark A, Brennecke J, Bushati N, Russell RB, Cohen SM. Animal MicroRNAs confer robustness to gene expression and have a significant impact on 3'UTR evolution. Cell 2005;123(6):1133-1146.

41. Laurent LC, Chen J, Ulitsky I, Mueller FJ, Lu C, Shamir R, Fan JB, Loring JF. Comprehensive microRNA profiling reveals a unique human embryonic stem cell signature dominated by a single seed sequence. Stem Cells 2008;26(6):1506-1516.

42. Yeyeodu ST, Witherspoon SM, Gilyazova N, Ibeanu GC. A rapid, inexpensive high throughput screen method for neurite outgrowth. Curr Chem Genomics 2010;4:74-83.

43. Price RD, Oe T, Yamaji T, Matsuoka N. A simple, flexible, nonfluorescent system for the automated screening of neurite outgrowth. J Biomol Screen 2006;11(2):155-164.

44. Mitchell PJ, Hanson JC, Quets-Nguyen AT, Bergeron M, Smith RC. A quantitative method for analysis of in vitro neurite outgrowth. J Neurosci Methods 2007;164(2):350362.

45. Liang Y, Ridzon D, Wong L, Chen C. Characterization of microRNA expression profiles in normal human tissues. BMC Genomics 2007;8:166.

46. Du L, Schageman JJ, Subauste MC, Saber B, Hammond SM, Prudkin L, Wistuba, II, Ji L, Roth JA, Minna JD, Pertsemlidis A. miR-93, miR-98, and miR-197 regulate expression of tumor suppressor gene FUS1. Mol Cancer Res 2009;7(8):1234-1243.
47. Yoav Benjamini YH. Controlling the False Discovery rate: A Practical and Powerful Approach to Multiple Testing. Journal of the Royal Statistical Society Series B (Methodological) 1995;57(1):12. 